\title{
Review
}

\section{The toxicologic pathology aspects of selected natural herbal products and related compounds}

\author{
Ruba Ibrahim ${ }^{1,2}$, Abraham Nyska ${ }^{3}$ 4*, June Dunnick$^{5}$, and Yuval Ramot'1,2 \\ ${ }^{1}$ Faculty of Medicine, Hebrew University of Jerusalem, Jerusalem, Israel \\ ${ }^{2}$ Department of Dermatology, Hadassah Medical Center, Jerusalem, Israel \\ ${ }^{3}$ Consultant in Toxicologic Pathology, Yehuda HaMaccabi 31, floor 5, Tel Aviv 6200515, Israel \\ ${ }^{4}$ Tel Aviv University, Tel Aviv, Israel \\ 5 Toxicology Branch, Division of the National Toxicology Program, National Institute of Environmental Health Sciences, Research \\ Triangle Park, NC, USA
}

\begin{abstract}
Herbal products have been in use for many years, but they are becoming more and more popular in recent years, and they are currently in widespread use throughout the world. In this review article we describe the histopathologic findings found after exposure to 12 dietary herbals in studies conducted in rodent model systems. Clear or some evidence for carcinogenic activity was seen with 6 herbals, with the liver being the most common organ affected. The intestine was affected by two herbals (aloe vera nondecolorized extract and senna), three had no clear evidence for carcinogenic activity and one was cardiotoxic (Ephedrine and Ephedra in combination with caffeine). Information from these studies can help to better understand potential target organs for further evaluation from exposure to various herbal products. (DOI: 10.1293/tox.2021-0016; J Toxicol Pathol 2021; 34: 181-211)
\end{abstract}

Key words: green tea extract, herbal medicine, toxicity, carcinogenicity, pathology, toxicologic pathology

\section{Introduction}

The use of natural products to treat disease has a long history ${ }^{1,2}$, and there is continued interest in using herbals as therapeutic agents. While herbals may be considered as "disease treatments" most are not licensed as drugs. This review describes the histopathologic findings from exposure to herbals in rodent model systems. Findings from such model studies are used by international groups to classify the potential for carcinogenic activity from various environmental exposures including herbals.

For example, the U. S. Food and Drug Administration regulates herbals as dietary supplements under the Dietary Supplement Health and Education Act of 1994 (DSHEA)3. As part of the 1994 DSHEA Act, the National Institutes of Health Office of Dietary Supplements (https://ods.od.nih. gov/) was created with a mission to understand and evaluate scientific information on natural herbal products or supplements ${ }^{4}$. Supplements in use prior to 1994 were generally

Received: 11 March 2021, Accepted: 17 March 2021

Published online in J-STAGE: 29 March 2021

*Corresponding Author: A Nyska (e-mail: anyska@nyska.net)

(C)2021 The Japanese Society of Toxicologic Pathology

This is an open-access article distributed under the terms of the Creative Commons Attribution Non-Commercial No Derivatives (c) $(\$$ (by-nc-nd) License. (CC-BY-NC-ND 4.0: https:// (CC) considered to be safe, but if new safety concerns are found, these are to be reported to the FDA4 . Many other countries, such as Israel, follow similar regulations for herbal remedies $^{5}$.

Rodent hazard identification toxicology studies are conducted on herbal products, because of their widespread use $^{6}$ and lack of toxicity information. We have previously reviewed the findings from herbal studies 7 , and in this review article we compare the treatment-related histopathologic findings from rodent studies of 12 dietary herbals. This includes six herbals that showed clear or some evidence for carcinogenic activity (Table 1); two that target the intestine (Table 2); three that did not show clear or some evidence for carcinogenic activity (Table 3); and one that caused cardiotoxicity (Table 4).

As it is a relatively common target organ in humans $\mathbf{s}^{8,9}$, the liver was also the most frequent site for carcinogenic activity after exposure to the six herbals causing carcinogenic activity in the rodent (goldenseal root power ${ }^{10}$, gingko biloba extract ${ }^{11}$, riddelliine ${ }^{12}$, pulegone ${ }^{13}$, kava kava ${ }^{14}$, and indole-3-carbino ${ }^{15}$ ). With some of these six herbals other sites of carcinogenic activity were also seen as well as a variety of nonneoplastic lesions (Table 1). The International Agency for Research on Cancer has reviewed the evidence for carcinogenic activity for four of these herbals (goldenseal, gingko, kava, and pulegone), and has classified these herbals as "possibly carcinogenic to humans" (Group 2B) because of evidence for carcinogenic activity in two species or both 


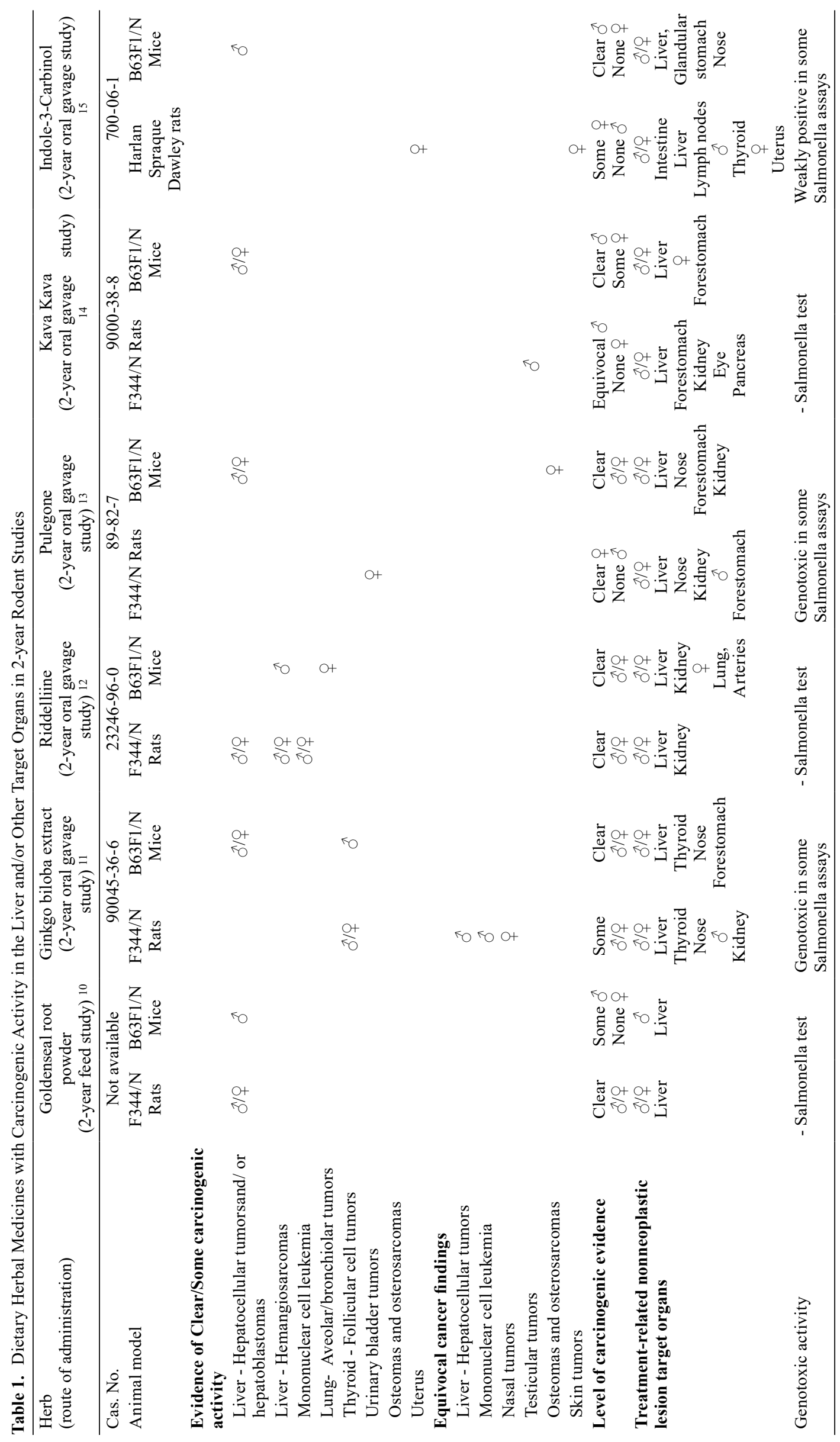


Table 2. Dietary Herbal Medicines with Toxic and/or Carcinogenic Activity in the Intestine in Rodent Studies

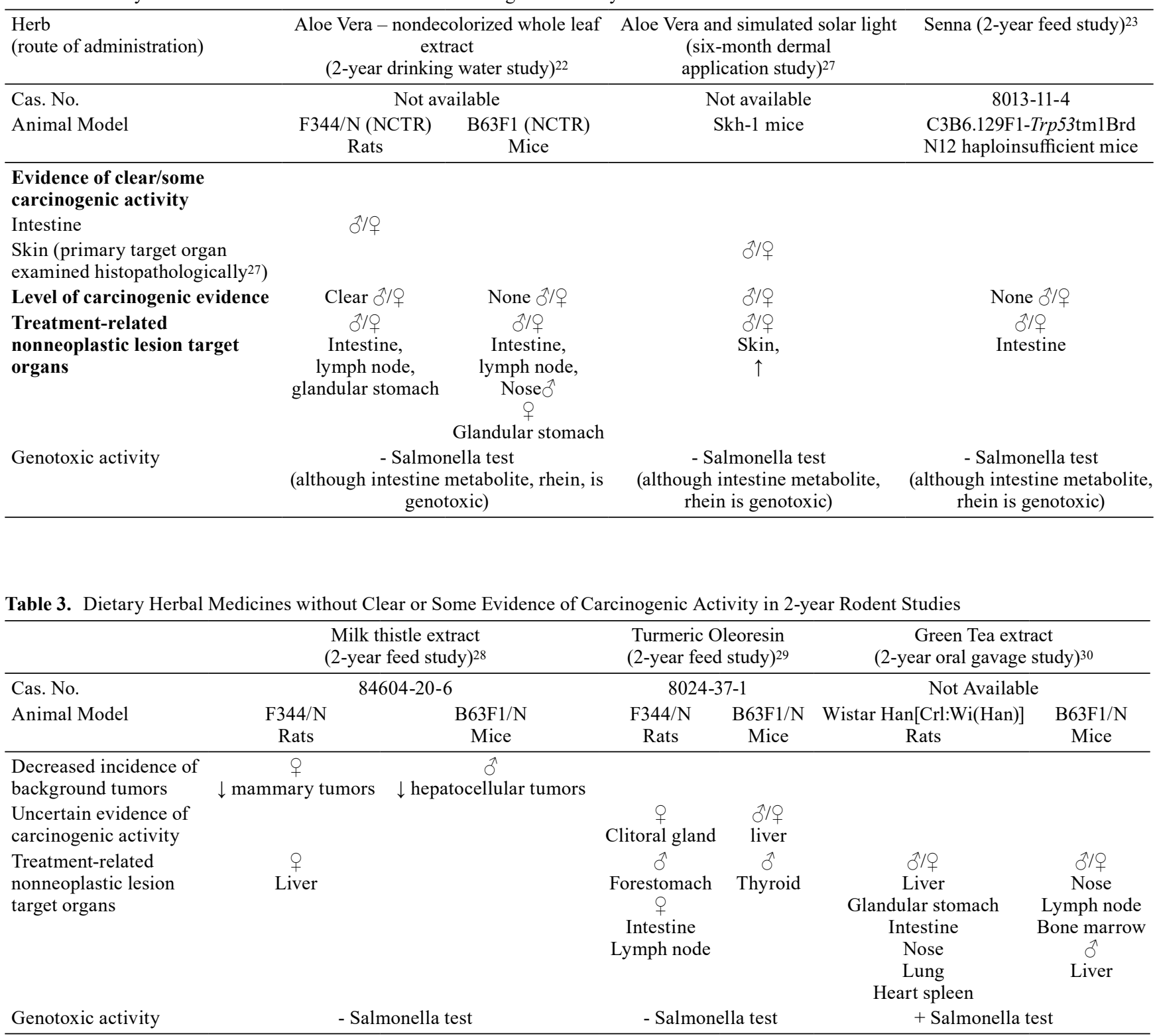

Table 4. Percent Survival and Incidence of Cardiotoxic Lesions in Male F344 Rats after One Dose of Ephedrine/Caffeine or Ephedra (Ma Huang)*/Caffeine (Oral Gavage Administration) ${ }^{36}$

\begin{tabular}{|c|c|c|c|c|c|c|c|c|c|c|c|c|c|c|}
\hline Ephedrine (mg/kg) & 0 & 0 & 0 & 6.25 & 6.25 & 12.5 & 12.5 & 12.5 & 12.5 & 25 & 25 & 25 & 25 & \\
\hline Caffeine $(\mathrm{mg} / \mathrm{kg})$ & 0 & 15 & 30 & 0 & 30 & 0 & 7.25 & 15 & 30 & 0 & 7.25 & 15 & 30 & \\
\hline $\begin{array}{l}\text { Heart - } \\
\text { and/or c }\end{array}$ & 0 & 1 & 5 & 5 & $5 \%$ & $0 \%$ & $0 \%$ & $5 \%$ & $5 \%$ & $20 \%$ & $45 \%$ & $45 \%$ & $50 \%$ & * \\
\hline$\%$ Survival & $0 \%$ & $100 \%$ & $100 \%$ & $100 \%$ & $100 \%$ & $100 \%$ & $100 \%$ & $95 \%$ & $100 \%$ & $90 \%$ & $65 \%$ & $70 \%$ & $55 \%$ & \\
\hline Ephedr & 0 & 0 & 0 & 0 & $\begin{array}{c}312.5 \\
(12.5)^{* *}\end{array}$ & $\begin{array}{l}312.5 \\
(12.5)\end{array}$ & $\begin{array}{l}312.5 \\
(12.5)\end{array}$ & $\begin{array}{l}312.5 \\
(12.5)\end{array}$ & $\begin{array}{l}625 \\
(25)\end{array}$ & $\begin{array}{l}625 \\
(25)\end{array}$ & $\begin{array}{l}625 \\
(25)\end{array}$ & $\begin{array}{l}1250 \\
(50)\end{array}$ & $\begin{array}{l}1250 \\
(50)\end{array}$ & $\begin{array}{l}1250 \\
(50)\end{array}$ \\
\hline Caffeine $(\mathrm{mg} / \mathrm{kg})$ & 0 & 15 & 30 & 45 & 0 & 15 & 30 & 45 & 0 & 15 & 30 & 0 & 15 & 30 \\
\hline $\begin{array}{l}\text { Heart - hemorrhag } \\
\text { and/or degeneratic }\end{array}$ & $5 \%$ & $0 \%$ & $5 \%$ & $5 \%$ & $0 \%$ & $5 \%$ & $20 \%$ & $5 \%$ & $0 \%$ & $30 \%$ & $25 \%$ & $35 \%$ & $95 \%$ & $85 \%$ \\
\hline$\%$ Survival & $100 \%$ & $100 \%$ & $100 \%$ & $100 \%$ & $100 \%$ & $100 \%$ & $95 \%$ & $95 \%$ & $100 \%$ & $75 \%$ & $75 \%$ & $70 \%$ & $90 \%$ & $85 \%$ \\
\hline
\end{tabular}

* Ephedra (Ma Huang) contained $4 \%$ by weight of ephedrine.

** Amount of ephedrine $(\mathrm{mg} / \mathrm{kg}$ ) in the Ephedra (Ma Huang) exposure.

*** no additional exposure for ephedrine/caffeine in this box. 
sexes of the same rodent species ${ }^{16}$.Three of these herbals (goldenseal, riddelliine, and pulegone) are on the California Proposition list as having the potential to cause cancer ${ }^{17}$.

Studies of the active ingredients in some of these herbals provide information that add to our understanding of mechanisms of carcinogenic activity observed in the rodent studies. Berberine is one of the major alkaloids in goldenseal and has been found to inhibit topoisomerase activity. Inhibition of topoisomerase activity can lead to DNA damage, a proposed mechanism for the goldenseal carcinogenic activity in rats and mice ${ }^{18}$. While systematic toxicologic studies of individual components of ginkgo have not been performed, other studies on molecular changes in ginkgoinduced rodent tumors indicate that cancer pathways have been disrupted. Transcriptomic analysis of ginkgo-induced liver tumors showed dysregulation of the Wnt pathway, downregulation of tumor suppressor genes, and overexpression of oncogenes ${ }^{19}$. Other studies found dysregulation of micro RNAs in ginkgo-induced liver tumors, that were comparable to those altered in human hepatocellular tumors $^{20}$. Metabolites of riddelliine have been found to cause DNA adducts, which could eventually lead to DNA damage $^{12}$. Detailed studies on the carcinogenic mechanisms of pulegone have not been conducted, but because of the positive Salmonella test results, a genotoxic mechanism may be involved ${ }^{13}$. While the exact carcinogenic mechanisms for kava kava have not been identified, changes in metabolic processes are thought to be involved in the steps to carcinogenic activity ${ }^{21}$. Activation of the aryl hydrocarbon pathway and subsequent oxidative damage may play a part in the indole-3-carbinol pathway to cancer ${ }^{15}$.

Two of the herbals (Table 2) had the intestine as a target organ (aloe vera nondecolorized extract ${ }^{22}$ and senna ${ }^{23}$ ). Aloe vera whole leaf nondecolorized extract caused intestinal tumors in rats, primarily in the large intestine. However, while aloe vera whole leaf nondecolorized extract caused intestinal nonneoplastic lesions in both rats and mice, no intestinal tumors occurred in mice (Table 2) 22 . Bacterial metabolism can break the beta-glycosidic bond of aloe vera in the intestine, and there is evidence that the rat microbiome has more of the active bacterial species causing this reaction in the gut than mice ${ }^{24}$. This was later confirmed by another study on aloin, a component of the aloe vera plant leaf, by showing similar pathophysiological effects ${ }^{25}$. Analysis of the rodent aloe vera intestinal tumors showed that some of the same point mutations as found in human colorectal cancers occurred, including mutations in Kras and Ctnnbl genes ${ }^{26}$. Aloe vera preparations given in conjunction with simulated solar light, increased the frequency of skin tumors in Skh-1 mice ${ }^{27}$. IARC has classified aloe vera as possibly carcinogenic to humans (group $2 \mathrm{~B})^{16}$. In a six month study of senna in a transgenic mouse model, intestinal lesions were seen, but these lesions did not progress to intestinal tumors ${ }^{23}$. Both aloe vera and the sennoside components of senna are metabolized by bacterial enzymes to rhein, a mutagenic component $^{22,23}$. Based on the aloe vera study findings, rats appear to be more susceptible to intestinal tumor formation than mice, and this may be due to differences in intestinal microbial content ${ }^{24}$.

Milk thistle ${ }^{28}$, turmeric oleoresin ${ }^{29}$, and green tea ex$\operatorname{tract}^{30}$ studies did not provide clear evidence for carcinogenic activity in rodent model systems (Table 3). Even though these three herbals did not cause carcinogenic activity, there were several treatment-related nonneoplastic lesions, particularly after green tea extract (Table 3 ). Ongoing clinical trials $^{31}$ of turmeric or curcumin (a major component in turmeric) include studies for anticancer or antiviral activity ${ }^{32}$. Milk thistle and its active ingredient silymarin have a large number of ongoing clinical trial studies particularly for liver disease ${ }^{33}$, as does green tea ${ }^{34}$. The National Center for Complementary and Integrative Health, National Institutes of Health updates information on the use of herbal products in medicine on a continuing basis ${ }^{35}$.

Ephedrine and Ephedra in combination with caffeine were found to rapidly cause cardiotoxicity in a rodent model system (Table 4) ${ }^{36,37}$. Alterations in heart rate, temperature, and cardiac lesions occurred in rats after exposure to the ephedrine/caffeine combination ${ }^{37}$. Products containing ephedra have been deemed to be unsafe by the U. S. Food and Drug Administration ${ }^{3}$.

None of the 12 natural herbal products reviewed in this paper are licensed as medicines in the United States. This review describes the pathology findings from the rodent model studies of these 12 herbal products.

\section{Ginkgo Biloba Extract11, 38}

Ginkgo is one of the oldest living tree species in the world, often referred to as a "living fossil". Ginkgo biloba extract (GBE) is an herbal supplement that has been used worldwide for decades. GBE is part of a complex mixture, which also includes flavonol glycosides and terpene lactones as the two other major components. The major flavonol glycosides are quercetin, kaempferol and isorhamnetin, which were identified to be mutagenic ${ }^{39}$.

Ginkgo biloba is commonly used as part of the diet and for medicinal purposes. Ginkgo seeds are consumed in Japan, China, and Korea to treat pulmonary disorders, alcohol abuse and urinary bladder infections, and Ginkgo leaves are used for lung and heart diseases as well as for skin infections. GBE has also been used for the treatment of earlystage Alzheimer's disease, vascular dementia, peripheral claudication, and tinnitus of vascular origin ${ }^{11,39}$.

Gingko can increase bleeding risk, especially when used in combination with antiplatelet agents or warfarin.

Several mechanisms of action identified in in vitro and in vivo studies are hypothesized to play a role, with antagonism of platelet activating factor (PAF) by the ginkgolides and the antioxidant action of the flavonoids being the most central ones ${ }^{40}$. The precise pharmacokinetic profile remains undetermined ${ }^{11}$.

Animals were administered GBE with corn oil vehicle at dosing volumes of $2.5 \mathrm{ml} / \mathrm{kg}$ for rats and $5 \mathrm{ml} / \mathrm{kg}$ for mice for 5 days per week. In the 3-month studies, groups of 10 
males and 10 females per treatment were administered GBE at doses of $0,62.5,125,250,500$, and $1,000 \mathrm{mg} / \mathrm{kg}$ for rats and $0,125,250,500,1,000$, or $2,000 \mathrm{mg} / \mathrm{kg}$ for mice. In the 2-year studies, groups of 50 males and 50 females per treatment received GBE at doses of $0,100,300$, and $1,000 \mathrm{mg} /$ $\mathrm{kg}$ (rats) or doses of $0,200,400$, and 2,000 mg/ $\mathrm{kg}$ (mice). A special study designed to assess thyroid hormone concentrations at 2 time points (day 22 and week 14) consisted of groups of 10 male and 10 female rats per treatment per time point and received the same doses as in the 2-year rat study for up to 14 weeks.

\section{Pathology findings}

3-month study in rats

Liver: Hepatocyte hypertrophy and fatty changes were observed in both male and female rats. Minimal to moderate hepatocyte hypertrophy, characterized by an increase in the amount of cytoplasm and in nuclear size, resulted in enlargement of the cells up to 1.5 times the normal size. Hepatocyte hypertrophy was observed initially in the centrilobular area with extension to the midzonal areas. Fatty changes were localized to scattered cells in the midzonal area and was characterized by large and clear lipid droplets that filled almost all the cell cytoplasm.

Thyroid: Hypertrophy was also observed in thyroid gland follicular cells, which resulted in a tall cuboidal or low columnar shape of the affected cells. Some of the cells showed increased clear vacuolation due to increased resorption of colloid.

Nose: The olfactory epithelium of the nose showed hyperpigmentation due to golden brown pigment accumulation within macrophages in the basal layer of the epithelium, and there was a trend towards atrophy of the olfactory epithelium in female rats.

3-month study in mice

Liver: Hepatocyte hypertrophy was also observed in mice, showing similar characteristics as the rats. In addition, there was an increase in focal hepatic necrosis in male mice, which was minimal in severity and was characterized by minute foci of hepatocytes with fragmented or pyknotic nuclei and brightly eosinophilic cytoplasm.

Nose: Nasal lesions were also observed in mice and included accumulation of hyaline droplets in the respiratory and olfactory epithelium, and pigmentation and hyaline droplet accumulation in the olfactory epithelium.

2-year study in rats

Liver: In comparison to historical control range, there were increased incidences of hepatocellular adenomas in groups exposed to gingko, but the incidences were not significantly different from the concurrent control group. Hepatocellular adenomas were well circumscribed and composed of hepatocytes with varied characteristics (i.e., basophilic, eosinophilic, vacuolated or an admixture) and sizes. Other changes observed in the livers of treated rats included bile duct hyperplasia and hepatocyte hypertrophy, focal fatty change in females (Fig. 1) and oval cell hyperplasia, necrosis, and cystic degeneration in males.

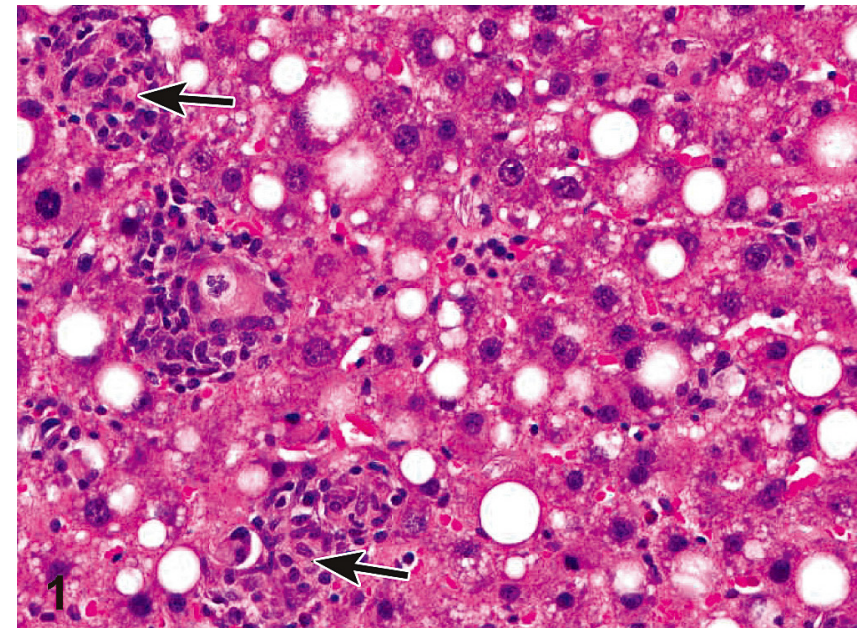

Fig. 1. Photomicrograph of H\&E-stained liver section showing fatty changes in the liver of a female F344/N rat administered 1,000 $\mathrm{mg} / \mathrm{kg}$ GBE by gavage for 2 years. Note the hepatocytes displaying microvesicular and macrovesicular fatty changes associated with microgranulomas (arrows) scattered throughout the lesion. The microgranulomas are composed predominantly of macrophages with fewer lymphocytes, plasma cells, and occasional neutrophils. The macrophages often contained fine, acicular clefts (cholesterol clefts). Reproduced with permission from Rider et al., Toxicity and carcinogenicity studies of Ginkgo biloba extract in rat and mouse: liver, thyroid, and nose are targets. Toxicol Pathol. 2014; 42(5): 830-43.

Thyroid: Thyroid follicular cell hypertrophy and hyperplasia were observed in all treated groups of rats (Fig. 2A-C). Hyperplasia was not diffuse, but rather focal or multifocal in nature, and the hyperplastic foci were not encapsulated and led to only minimal compression of adjacent thyroid follicles. No mitotic figures or atypia was observed. The follicular cell hyperplasia was characterized by crowding of the cells in the basal layer of the epithelium, which showed cuboidal to low columnar appearance. Some follicles were enlarged with increased colloid, and in some papillary projections of the epithelium were observed. Wellcircumscribed and non-encapsulated follicular cell adenomas of the thyroid gland were observed in male and female rats (Fig. 2D). They were generally small and did not lead to compression of the adjacent tissue. The neoplastic cells were hyperchromatic, varied in shape from cuboidal to columnar, and there was an increase in nucleus-to-cytoplasm ration. These cells led to the formation of follicles that contained colloid. The neoplastic cells formed papillary projections that protruded into the lumens of dilated cystic follicles. Follicular cell carcinoma was evident in two females and was characterized by highly cellular large lesions that contained atypical cells and high mitotic activity (Fig. 2E). Some of the lesions showed invasion.

Nose: Nasal lesions were also observed in the rats, including atrophy and metaplasia in the olfactory epithelium, hyperplasia in transitional and respiratory epithelium, pigmentation of the olfactory epithelium, atrophy of nerves in 

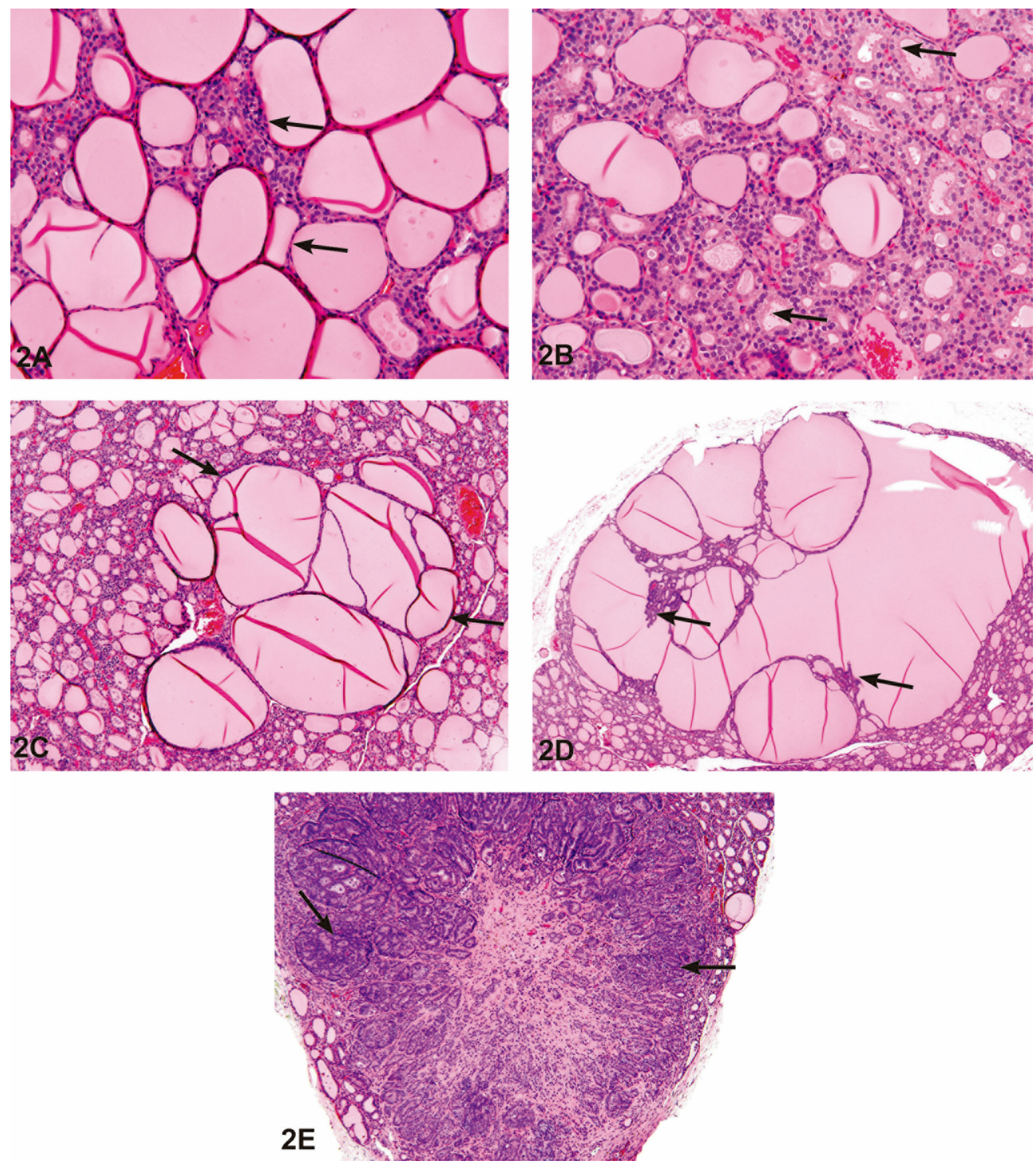

Fig. 2. Photomicrograph of $H \& E$ stained thyroid gland sections taken from 2 -year F344/N rat study of GBE. A: Normal thyroid gland follicles from a male vehicle control F344/N rat. Most of the follicles are lined by flattened epithelium (arrows) and the follicles are distended with homogeneous colloid. B: Thyroid gland follicular cell hypertrophy in a female F344/N rat administered 1,000 mg $/ \mathrm{kg}$ GBE. Most of the follicles are lined by cuboidal epithelium (arrows), and there is a decreased amount of colloid as compared to Fig. 2A. C: Thyroid gland follicular cell hyperplasia in a male F344/N rat administered $1,000 \mathrm{mg} / \mathrm{kg}$ GBE. Note the focal enlargement of follicles that typically compress the surrounding parenchyma (arrows). The follicles are lined by epithelial-lined septae, and papillary projections frequently project into the follicular colloid. D: Thyroid gland follicular cell adenoma in a male F344/ $\mathrm{N}$ rat administered 1,000 mg $/ \mathrm{kg} \mathrm{GBE}$. The adenoma tends to be larger with more compression of the adjacent parenchyma and more complex epithelial infoldings than in hyperplasia (arrows). E: Thyroid gland follicular cell carcinoma in a female F344/N rat administered $300 \mathrm{mg} / \mathrm{kg}$ GBE. The neoplasm is highly cellular (arrows) with local invasion. Reproduced with permission from Rider et al., Toxicity and carcinogenicity studies of Ginkgo biloba extract in rat and mouse: liver, thyroid, and nose are targets. Toxicol Pathol. 2014; 42(5): 830-43. 
the olfactory epithelium, hyperplasia of goblet cells in the respiratory epithelium, decrease in hyaline droplet accumulation and chronic active inflammation (Fig. 3).

2-year study in mice

Liver: Several non-neoplastic lesions were related to GBE exposure, including hematopoietic cell proliferation, hepatocyte hypertrophy, inflammation, erythrophagocytosis, cytoplasmic vacuolization and necrosis. Neoplastic lesions that were related to GBE exposure included hepatocellular adenoma, hepatocellular carcinoma and hepatoblastoma of the liver.

Thyroid: Thyroid follicle hyperplasia and follicular cell hypertrophy was also connected to GBE exposure, in addition to four cases of thyroid gland follicular cell adenoma.

Nose: Additional lesions connected to GBE exposure included pigmentation of the olfactory epithelium and accumulation of hyaline droplet in the nose.

\section{Green tea ${ }^{30}$}

Green tea extract is obtained from leaves of the plant Camellia sinensis of the Theaceae family.

Approximately $10 \%$ of the dry weight of green tea is made up of catechins, mainly epicatechin, epicatechin3-gallate, epigallocatechin, and epigallocatechin-3-gallate (EGCG), with EGCG being the highest in concentration. These are considered to be the active compounds in green tea.

It has attracted great interest due to its potential beneficial effects, including antioxidative, anti-inflammatory, anticarcinogenic, thermogenic, probiotic, and antimicrobial properties. It may be consumed as dilute beverages, concentrated supplement, or as topical application.

Although considered nontoxic, several potential adverse effects were reported in animal and in vitro studies. These include dermal and eye irritation, as well as hepatic necrosis and intestinal toxicity (e.g., intestinal dilatation and small intestinal hemorrhagic fluid).

Green tea consumption was associated with acceleration of skin tumors in mice and increased amounts of the glutathione S-transferase placenta-form positive liver foci in a multiorgan rat carcinogenesis model. In humans, green tea was associated with increased lung cancer risk and teratogenicity (neural tube defects and anencephaly). Increased consumption of green tea also caused increased hepatocellular liver enzymes with one case resulting in liver failure. The mechanism of hepatotoxicity is still unknown.

The NTP three-month study in F344/NTac Rats and in mice included groups of 10 male and 10 female core study rats were administered $0,62.5,125,250,500$, or $1,000 \mathrm{mg}$ green tea extract $/ \mathrm{kg}$ body weight in deionized water by gavage, 5 days per week for 14 weeks

Two-year Study in Wistar Han Rats included groups of 60 male and 60 female rats that were administered 0 or $1,000 \mathrm{mg}$ green tea extract $/ \mathrm{kg}$ body weight and groups of 50 male and 50 female rats were administered 100 or $300 \mathrm{mg}$ / $\mathrm{kg}$ in deionized water by gavage, 5 days per week for up to
105 weeks. Groups of 50 male and 50 female mice were administered $0,30,100$, or $300 \mathrm{mg}$ green tea extract $/ \mathrm{kg}$ body weight in deionized water by gavage, 5 days per week for 105 weeks.

\section{Pathology findings}

3-month study in rats 41

Liver: A single case of centrilobular necrosis was reported, showing hemorrhage, necrotic hepatocytes, and mononuclear infiltrate (Fig. 4). The necrotic hepatocytes were characterized by eosinophilic or vacuolated condensed cytoplasm and karyorrhectic and pyknotic nuclei. The necrosis was associated with mild chronic inflammation. Additionally, signs of post-necrotic regeneration were evident in several rats, and consisted of oval cell hyperplasia, bile duct hyperplasia, golden brown pigment accumulation in Kupffer cells and higher numbers of midzonal hepatocytes with mitotic figures. The Kupffer cells stained positive for PAS, Schmorl's and Prussian Blue, indicating the presence of glycoprotein, lipofuscin, and iron in the cells (Fig. 5). There was also periportal hypertrophy in some of the rats.

Nose: Chronic active inflammation was found in both male and female rats, involving the olfactory epithelium in the dorsal or dorsolateral meatus and the respiratory epithelium of the nasal septum or lateral wall. It was characterized mostly by neutrophils, with smaller numbers of plasma cells and lymphocytes in the lamina propria, that were found migrating via the epithelium into the airways or lumina of Bowman's glands. Necrosis of the olfactory epithelium was noted in the higher doses, associated with karyorrhexis and pyknosis of the nuclei and sloughing of the epithelium (Fig. 6).

Olfactory epithelial atrophy was seen mostly in the dorsal meatus of both male and female rats, together with olfactory nerve atrophy (Fig. 7). The nerve atrophy was commonly seen together with olfactory epithelial metaplasia to respiratory epithelium. Accumulation of golden-brown pigment was observed in the degenerating olfactory epithelium and in histiocytes in the lamina propria, which was positive for Schmorl's and PAS stains (Fig. 8). Respiratory epithelial hyperplasia (greater than three cell layers of non-ciliated cuboidal epithelium) was also noted in the nasal septum or lateral wall.

Bowman's gland hyperplasia was seen in the olfactory epithelium, and was characterized by nodular proliferations of the cells, leading to compression of the glandular lumina (Fig. 9). Pharyngeal duct degeneration was seen sporadically, characterized by the transformation of the cells from a columnar shape to a more attenuated or cuboidal cells (Figs. 10 and 11). Some cases were accompanied by an inflammatory infiltrate composed of neutrophils and occasionally mononuclear cells.

Thymus: Minimal thymic atrophy was observed in the higher dose due to apoptosis and loss of T cell lymphocytes, leading to thinning of the cortex.

3 -month study in mice ${ }^{41}$

Liver: Liver necrosis was seen in both male and female 

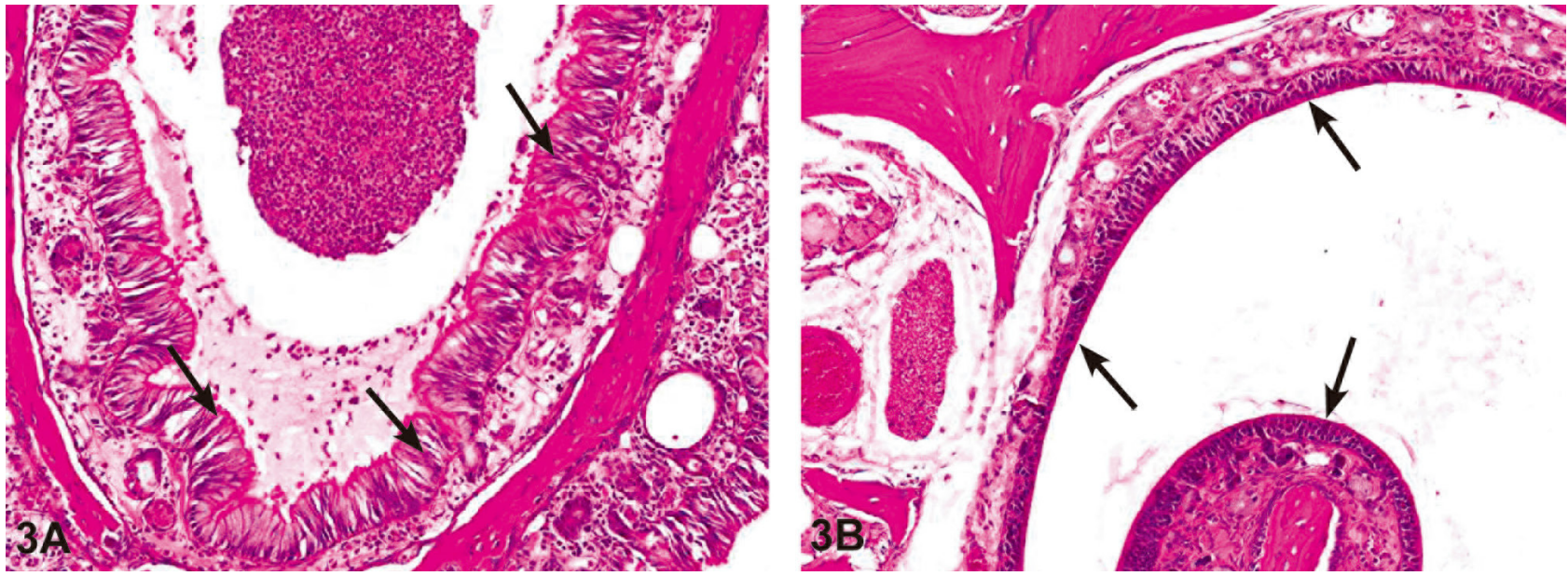

Fig. 3. A: Photomicrograph of H\&E-stained nasal tissue sections taken from 2-year F344/N rat study of GBE. Chronic active inflammation in the nose of a female F344/ $\mathrm{N}$ rat administered $1,000 \mathrm{mg} / \mathrm{kg}$ GBE. Note the presence of mixed inflammatory infiltrate that involves the submucosa and the lumen of the nasal cavity. There is also respiratory metaplasia of the olfactory epithelium (arrows). B: Atrophy of the olfactory epithelium in the nose (Level III) of a female F344/ $\mathrm{N}$ rat administered $1,000 \mathrm{mg} / \mathrm{kg}$ GBE. Note the thinning and disorganization of the olfactory epithelial layer (arrows). Reproduced with permission from Rider et al., Toxicity and carcinogenicity studies of Ginkgo biloba extract in rat and mouse: liver, thyroid, and nose are targets. Toxicol Pathol. 2014; 42(5): 830-43.

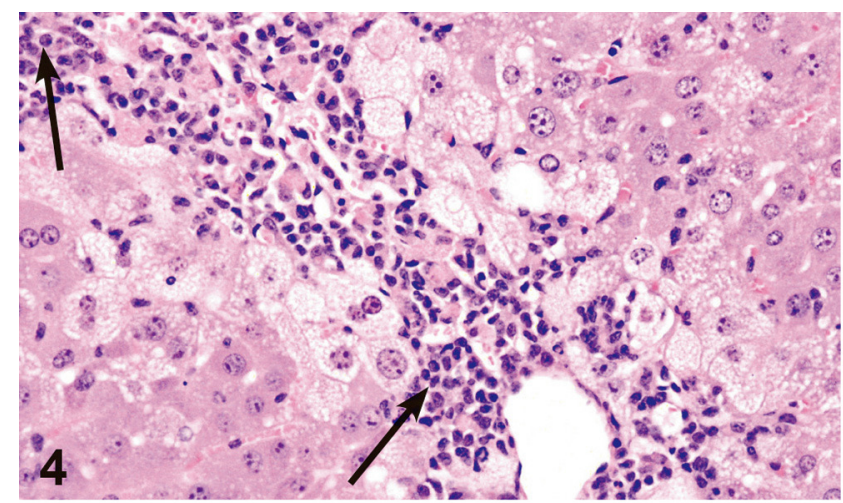

Fig. 4. Chronic inflammation (arrows) bordered by vacuolated hepatocytes (fatty change), in a female rat administered 1,000 $\mathrm{mg} / \mathrm{kg}$ green tea extract (GTE) by gavage for 3 months. H\&E, $\times 20$. Reproduced with permission from Chan et al., Toxicol Pathol. 2010; 38(7): 1070-84.

mice in the high doses. Centrilobular to panlobular necrosis and hemorrhage were observed, and fatty change were seen in several female mice in hepatocytes bordering the necrotic area (Fig. 12). In some cases, the necrosis was accompanied by inflammation, characterized by the presence of plasma cells, lymphocytes, and macrophages. Increased mitosis of hepatocytes was observed in the intervening region between the centrilobular and the periportal regions. Karyomegalic hepatocytes were observed in a few mice with minimal levels of necrosis and were in the midzonal regions between the centrilobular and periportal areas (Fig. 13).

Nose: Similar changes to the ones observed in rats occurred in mice, including olfactory epithelium atrophy, olfactory nerve atrophy, and metaplasia of olfactory epitheli-

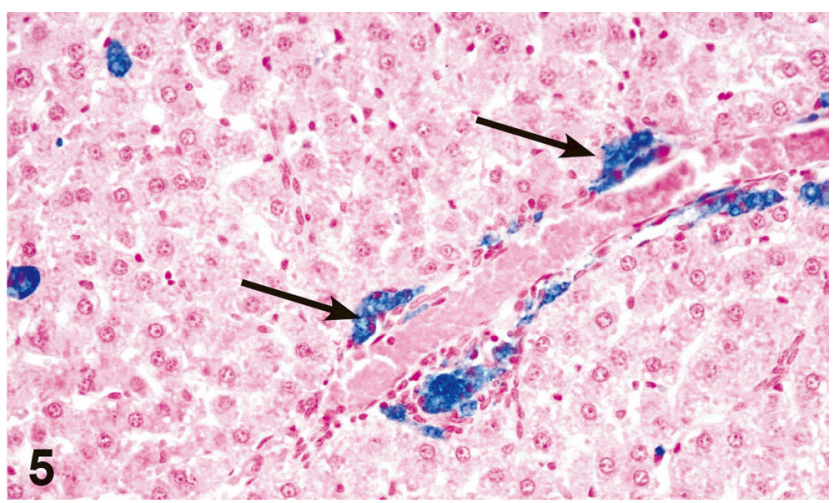

Fig. 5. Prussian Blue positive (detecting ferritin) pigment accumulation in Kupffer cells in the liver of a female rat administered $1,000 \mathrm{mg} / \mathrm{kg}$ green tea extract (GTE) by gavage for 3 months (arrows). The pigment was also positive for ceroid lipofuscin (Schmorl's staining) and glycoproteins (PAS staining). Prussian Blue, $\times 20$. Reproduced with permission from Chan et al., Toxicol Pathol. 2010; 38(7): 1070-84.

um to respiratory epithelium (Fig. 14). In addition, olfactory epithelial necrosis was observed in male and female mice, characterized by loss of pyknosis and karyorrhexis of olfactory epithelial nuclei and loss of olfactory sensory epithelial cells. This change was accompanied by infiltrates of neutrophils and smaller numbers of lymphocytes and plasma cells. Respiratory epithelial necrosis was seen only sporadically in males and females, and this change was also accompanied by an inflammatory infiltrate. Basal cell hyperplasia of the olfactory epithelium was seen sporadically in males and females, and there was also an extension of hyperplastic cuboidal cells into the Bowman's glands, resembling a nodular proliferation of cells beneath the olfactory epithelium 


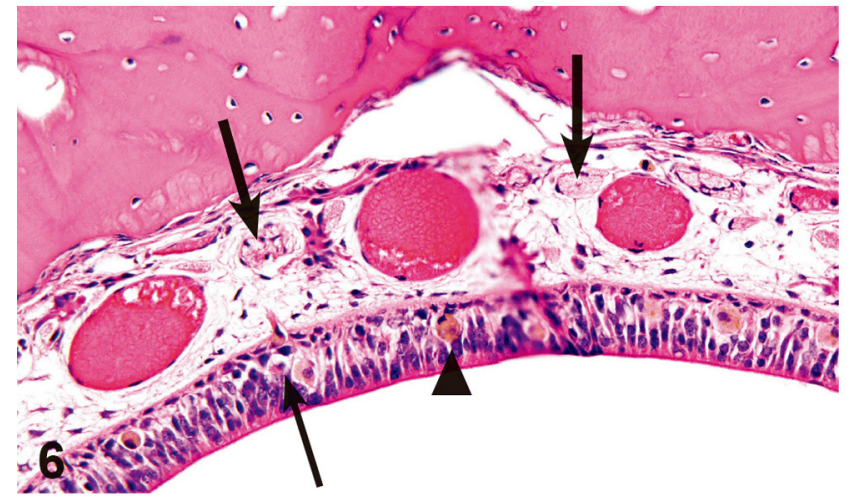

Fig. 6. Olfactory epithelium necrosis (thin arrow), atrophy, nerve fiber atrophy (thick arrows), and pigmented histiocytes (arrowhead) in the dorsal meatus of level II of the nasal cavity of a male rat administered with $1,000 \mathrm{mg} / \mathrm{kg}$ green tea extract (GTE) by gavage for 3 months. Compare with Fig. 4. H\&E, $\times 32$. Reproduced with permission from Chan et al., Toxicol Pathol. 2010; 38(7): 1070-84.

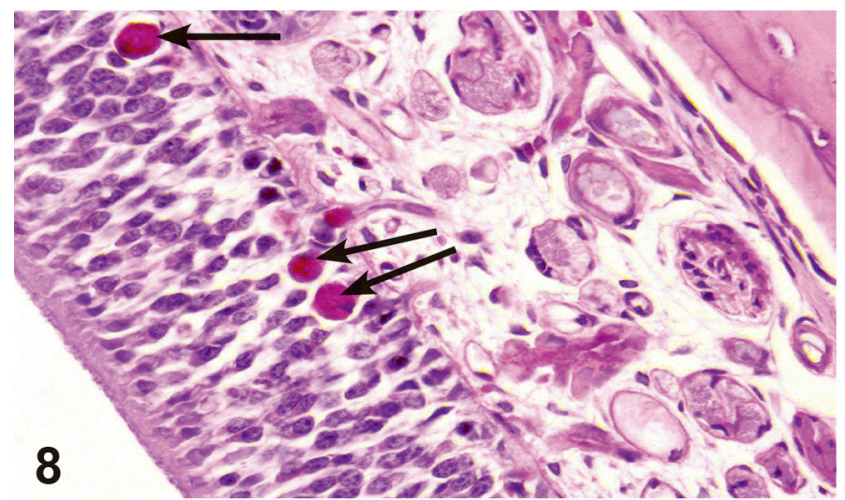

Fig. 8. Glycoproteins (PAS)-positive pigment accumulation in olfactory epithelium (arrows) of nasal cavity of a male rat administered $1,000 \mathrm{mg} / \mathrm{kg}$ green tea extract (GTE) by gavage for 3 months. The pigment was also positive for ceroid lipofuscin (Schmorl's staining). PAS, $\times 40$. Reproduced with permission from Chan et al., Toxicol Pathol. 2010; 38(7): 1070-84.

(Fig. 15). Hyaline droplet accumulation was observed in the respiratory epithelium.

Lymphoid organs: Splenic lymphoid atrophy, which was more pronounced in the white pulp, was seen in female mice, and was characterized by the loss of $\mathrm{T}$ cell lymphocytes in the periarteriolar lymphoid sheaths and B cells in the coronal follicles and the germinal centers (Figs. 16 and 17). Atrophy of the mandibular and mesenteric lymph nodes was also observed, characterized mainly by loss of $\mathrm{T}$ lymphocytes in the paracortex and B cells of the follicles. Thymic atrophy, which was characterized mainly by thinning of the cortex, was seen in males and females treated with the high dose of green tea extract. In few males and females, atrophy of the Peyer's patches was seen in the ileum, cecum, and/ or colon.

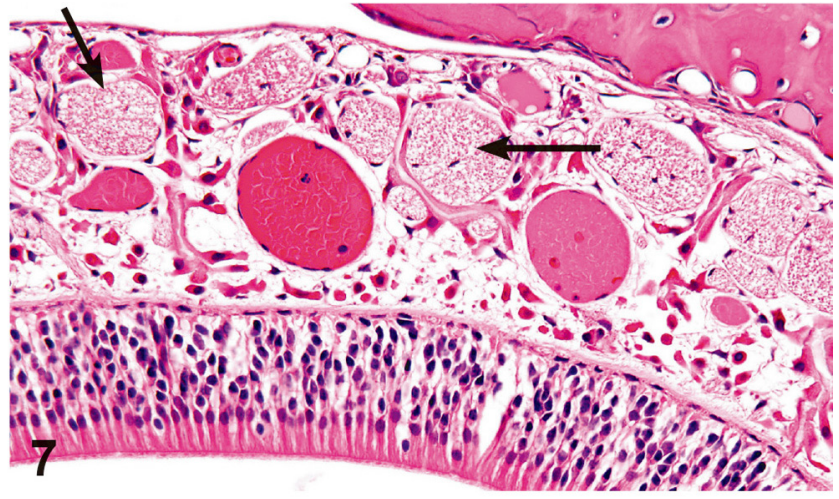

Fig. 7. Olfactory epithelium in the dorsal meatus of level II of the nasal cavity of a control rat from the 3-month green tea extract (GTE) gavage study. Note normal size and number of the olfactory nerves in the lamina propria (arrows). H\&E, $\times 32$. Reproduced with permission from Chan et al., Toxicol Pathol. 2010; 38(7): 1070-84.

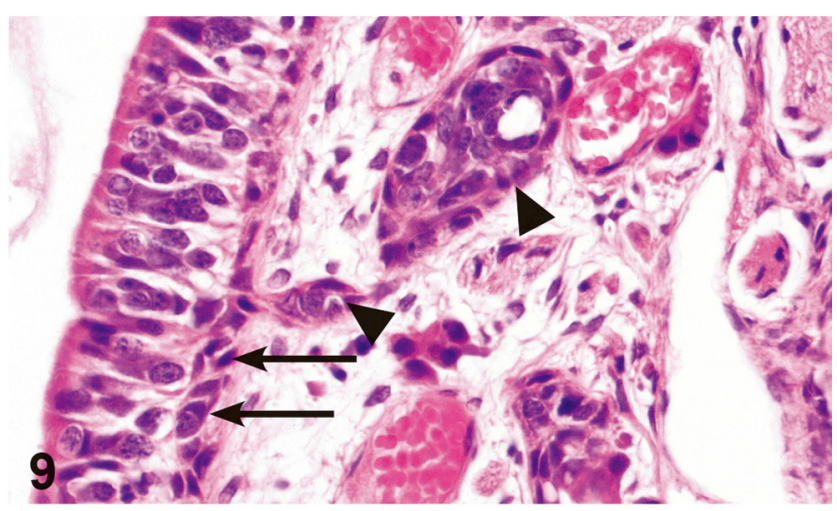

Fig. 9. Basal cell hyperplasia (arrows) and Bowman's gland hyperplasia (arrowheads) in the olfactory epithelium lining the dorsal meatus of level III of the nasal cavity of a male rat administered $1,000 \mathrm{mg} / \mathrm{kg}$ green tea extract (GTE) by gavage for 3 months. The basal cell hyperplasia is characterized by minimal proliferation ( $2-3$ cells thick) of basal cells. The Bowman's gland hyperplasia is characterized by nodular proliferation of cells that compressed and occasionally filled glandular lumina. H\&E, $\times 40$. Reproduced with permission from Chan et al., Toxicol Pathol. 2010; 38(7): 1070-84.

2-year study in rats 30

Liver: The incidences of necrosis and oval cell hyperplasia were significantly increased in the high dose males and females. The liver necrosis was characterized by both necrosis of individual hepatocytes and submassive to massive necrosis of hepatic parenchyma. There was no distinct pattern to the necrosis, though the less severe lesions were predominantly midzonal. Individual cell necrosis was characterized by rounding up and shrinkage of individual hepatocytes with nuclear condensation-pyknosis. In more severe lesions, individual cell necrosis was characterized 


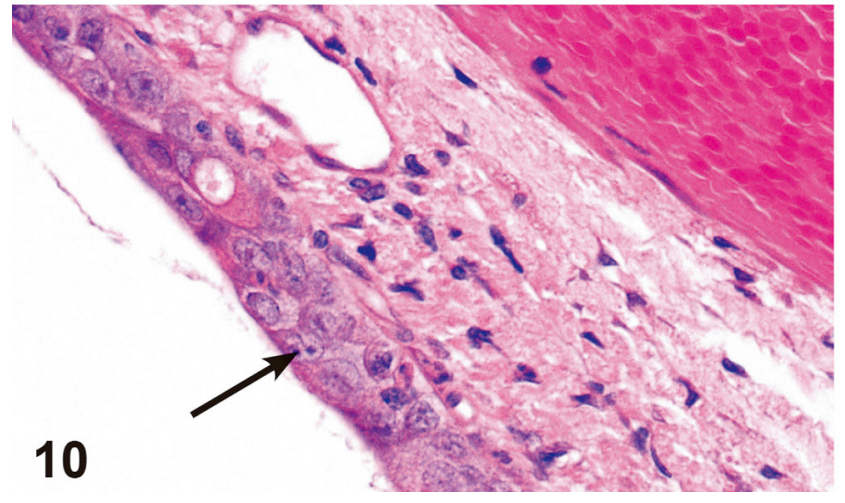

Fig. 10. Nasopharyngeal duct degeneration (arrow) located at level III of the nasal cavity of a male rat administered $500 \mathrm{mg} / \mathrm{kg}$ GTE by gavage for 3 months. The degeneration is characterized by decreased goblet cell numbers and transformation of tall columnar ciliated epithelial cells to more attenuated or cuboidal cells. Compare with Fig. 8. H\&E, $\times 4$. Reproduced with permission from Chan et al., Toxicol Pathol. 2010; 38(7): $1070-84$.

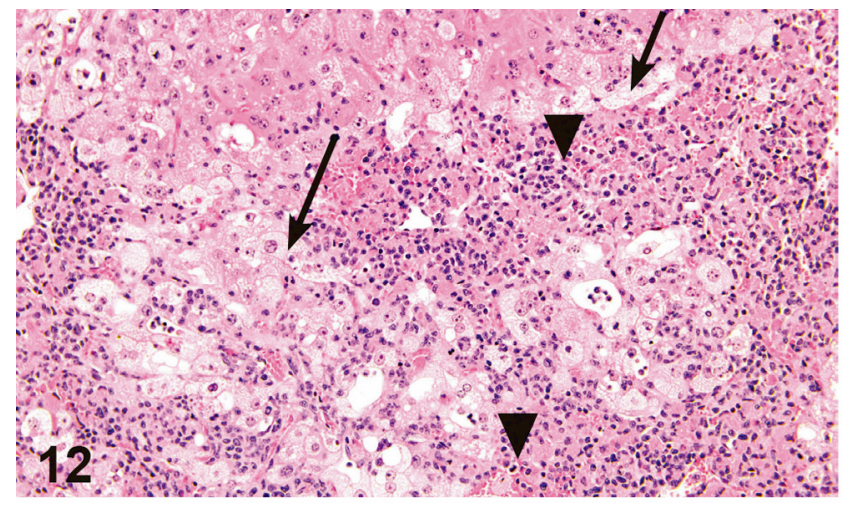

Fig. 12. Centrilobular hepatocellular inflammation (arrowheads) and fatty change (arrows) in a male mouse administered 1,000 $\mathrm{mg} / \mathrm{kg}$ green tea extract (GTE) by gavage. H\&E, $\times 20$. Reproduced with permission from Chan et al., Toxicol Pathol. 2010; 38(7): 1070-84

by swollen, hypereosinophilic hepatocytes with nuclear karyolysis-karyorrhexis; these lesions were associated with congestion, hemorrhage, cellular infiltrates (predominantly neutrophilic), and hypertrophy/hyperplasia of the Kupffer cells. Oval cell hyperplasia was primarily minimal and was characterized by increased cellularity, mostly within portal areas, with proliferation of small cells with scant cytoplasm and oval-shaped nuclei occasionally forming linear tracts, though not forming ducts.

Gastrointestinal tract: Necrosis of the glandular stomach mucosa was observed in male and female rats and was characterized by a variably thick zone of mucosa with shrunken, hypereosinophilic cytoplasm and nuclear pyknosis, which was accompanied by cell debris, congestion, hemorrhage, fibrin thrombi, and bacterial colonies in older

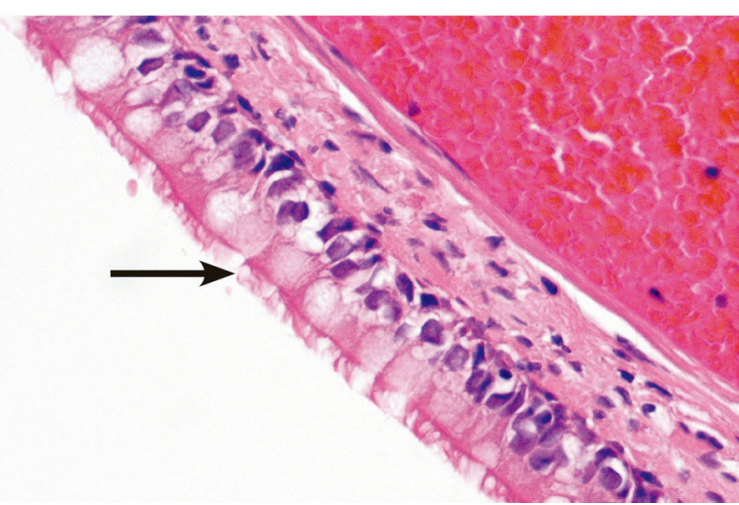

Fig. 11. Tall columnar, ciliated epithelium lining the nasopharyngeal duct (arrow) in level III of the nasal cavity of a male control rat from the 3-month green tea extract (GTE) gavage study. $\mathrm{H} \& \mathrm{E}, \times 40$. Reproduced with permission from Chan et al., Toxicol Pathol. 2010; 38(7): 1070-84.

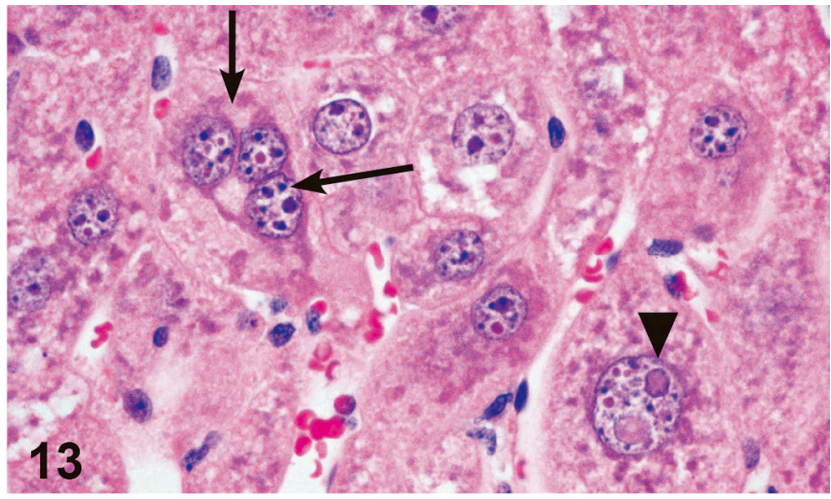

Fig. 13. Hepatocyte karyomegaly (arrowhead) and tri-nucleated hepatocyte (arrows) in a male mouse administered $1,000 \mathrm{mg} /$ $\mathrm{kg}$ green tea extract (GTE) by gavage for 3 months. H\&E, $\times 60$. Reproduced with permission from Chan et al., Toxicol Pathol. 2010; 38(7): 1070-84.

lesions. There were small numbers of treated animals with increased numbers of pigment-laden cells, and occasionally the pigment was darker brown and globular, consistent with hemosiderin and suggestive of prior hemorrhage. Mucosal necrosis was also seen in all the segments of the small intestine. Mucosal necrosis was characterized by excessive exfoliation of shrunken, hypereosinophilic epithelial cells with pyknotic nuclei at the tips or lateral aspect of villi, or variable lengths of shriveled intact villous epithelium lacking supporting lamina propria. In addition to changes to the mucosal epithelium, the capillaries of the subjacent lamina propria of affected villi were often markedly dilated and infrequently contained fibrin thrombi. Occasionally remaining villi showed evidence of regeneration characterized by unevenly spaced epithelial cells with variable amounts of 


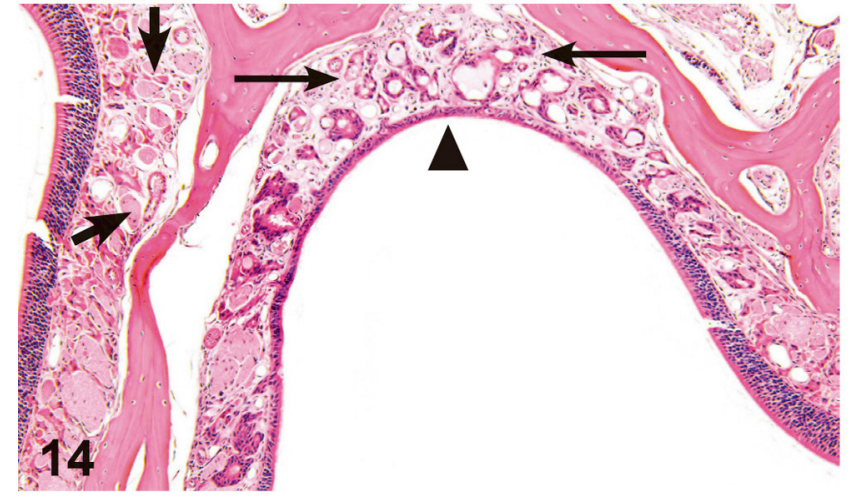

Fig. 14. Unilateral olfactory epithelium atrophy (arrowhead), olfactory nerve atrophy (thin arrows), and metaplasia of olfactory epithelium to respiratory epithelium in the dorsal meatus of level III in a male mouse administered $1,000 \mathrm{mg} / \mathrm{kg}$ green tea extract (GTE) by gavage for 3 months. Note the normal aspect of the olfactory nerves in the lamina propria of the unaffected side (thick arrows). H\&E, $\times 16$. Reproduced with permission from Chan et al., Toxicol Pathol. 2010; 38(7): 1070-84.

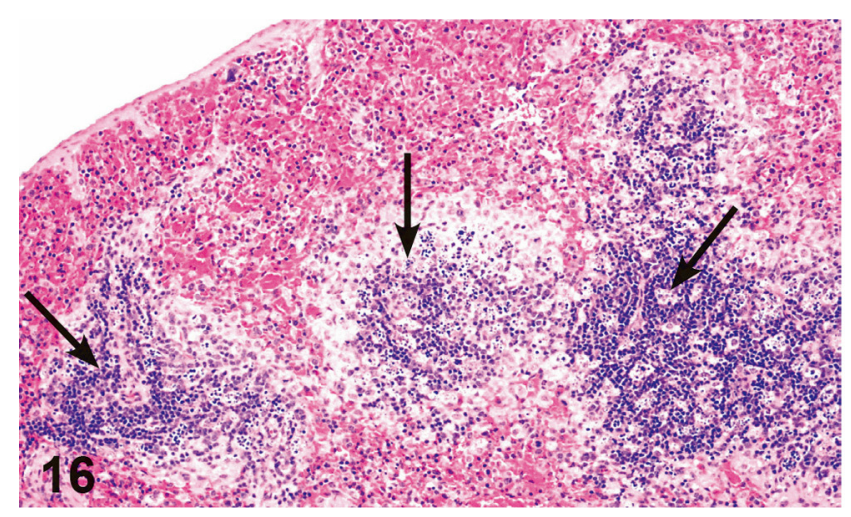

Fig. 16. Splenic white pulp atrophy. The arrows indicate reduced lymphoid cells in the periarteriolar lymphoid sheath corona and marginal zone of the white pulp in a female mouse administered $1,000 \mathrm{mg} / \mathrm{kg}$ green tea extract (GTE) by gavage for 3 months. H\&E, $\times 10$. Compare with Fig. 14. Reproduced with permission from Chan et al., Toxicol Pathol. 2010; 38(7): 1070-84.

cytoplasm and vesicular nuclei.

Nose: Lesions in the nasal lumen included increased incidences of suppurative inflammation in male and female rats and foreign material in female rats. Suppurative inflammation was characterized by accumulations of neutrophils within the lumen of the nasal passages. Some animals also had infiltrates of lymphocytes and plasma cells within the subepithelial stroma. The presence of foreign bodies within the nasal lumen consisted most often of pieces of plant material or hair shafts and occasionally other small refractile pieces of unidentifiable material. Typically, the foreign material was associated with a neutrophil-rich luminal exudate.

Nasopharyngeal duct lesions included degeneration,

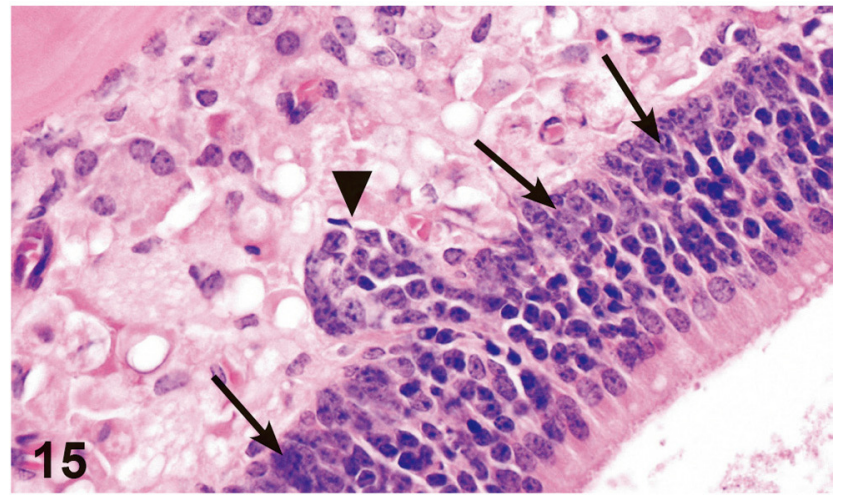

Fig. 15. Basal cell hyperplasia (arrows) and Bowman's gland hyperplasia (arrowhead) in the olfactory epithelium in the dorsal meatus of level III in a male mouse administered $1,000 \mathrm{mg} /$ $\mathrm{kg}$ green tea extract (GTE) by gavage for 3 months. Note the increased number of basal cells. Instead of a single layer of basophilic nuclei, the nuclei are piled up or crowded and extend up into the olfactory cells. The Bowman's gland hyperplasia is characterized by nodular proliferation of cells that compressed and occasionally filled glandular lumina in the lamina propria underlying or continuous with the olfactory epithelium. H\&E, $\times 40$. Reproduced with permission from Chan et al., Toxicol Pathol. 2010; 38(7): 1070-84.

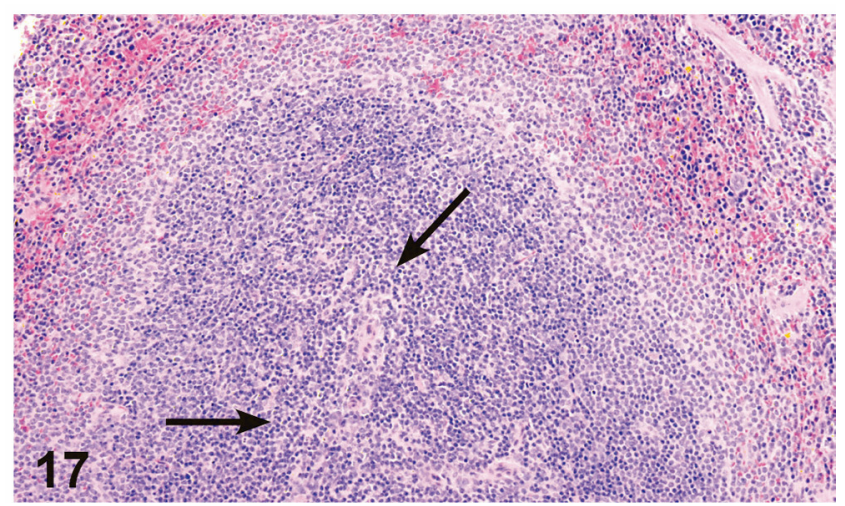

Fig. 17. Normal aspect of the splenic white pulp, and in particular the periarteriolar lymphoid sheaths (arrows), in a control female mouse from the 3-month green tea extract (GTE) gavage (compare with the previous photo). H\&E, $\times 4$. Reproduced with permission from Chan et al., Toxicol Pathol. 2010; 38(7): 1070-84.

hyperplasia, necrosis, and regeneration of the epithelium and suppurative inflammation within the duct itself. Necrosis was characterized by hypereosinophilia and cell swelling and often there were large sections of sloughed necrotic epithelium. Hyperplasia was characterized by increased height and nuclear layers within the epithelium often with epithelial infoldings or invaginations. Degeneration was characterized by epithelium that exhibited evidence of damage (e.g., cellular vacuolation and/or swelling) but was not to the point of necrosis. Regeneration was comparable to the 
aspect of this lesion seen in the respiratory epithelium. Suppurative inflammation in the nasopharyngeal duct was characterized by exudation of neutrophils within the nasopharyngeal duct lumen. Lamina propria of the nasopharyngeal duct changes consisted of pigmentation and mineralization. Pigmentation was characterized by variably sized clusters of histiocytes with abundant intracytoplasmic accumulation of golden to greenish brown pigmented material that were in the lamina propria generally associated with regions of bony proliferation/remodeling. Mineralization was associated with the basement membrane of both olfactory and respiratory epithelium. Larger foci consisted of pale irregular laminated material. Enlarged deposits of the mineralized material usually protruded into the lamina propria, but occasionally projected outward into the epithelium and rarely protruded into the nasal lumen.

Olfactory epithelial lesions included atrophy, necrosis, basal cell hyperplasia, respiratory and squamous metaplasia, and pigmentation. The incidence of atrophy of the nerves underlying the olfactory epithelium was also significantly increased in all dosed groups of male and female rats. Olfactory epithelial atrophy was characterized by focal to focally extensive regions of decreased numbers of cells in, and disorganization of, the nuclear layers, along with loss of the luminal eosinophilic border. Nerve atrophy was always associated with atrophy of the olfactory epithelium, though not all animals with epithelial atrophy had corresponding atrophy of the underlying nerve bundles. Olfactory epithelial necrosis was characterized by a segment or cluster of epithelial cells that were shrunken and hypereosinophilic with karyorrhexis and/or nuclear pyknosis. Olfactory basal cell hyperplasia was characterized by increased cell size and cell number of the basal cells of the olfactory epithelium, usually two to three cell layers in thickness, with the occasional formation of gland-like structures which extended down into the underlying Bowman's glands. Metaplasia was characterized by partial to complete loss and replacement of the olfactory epithelium by respiratory epithelium, or less commonly, by squamous epithelium. Occasionally, the metaplastic respiratory epithelium formed gland-like invaginations into the underlying stroma. The stroma underlying the affected metaplastic olfactory epithelium was altered in that there was a loss of Bowman's glands and atrophy of the olfactory nerve bundles. Pigmentation of the olfactory epithelium was characterized by abundant intracytoplasmic accumulation of golden-brown pigmented material within olfactory epithelial cells. These cells were most often present in regions of the epithelium that had atrophied or had evidence of prior damage and repair.

Respiratory epithelial lesions included atrophy, necrosis, squamous metaplasia, and pigmentation. Atrophy of the respiratory epithelium was characterized by flattening of the respiratory epithelium to a low cuboidal epithelium instead of the normal tall columnar epithelium. Degeneration of the respiratory epithelium was characterized by epithelium exhibiting evidence of damage (e.g., cellular vacuolation and swelling) but was not to the point of necrosis.
Necrosis was characterized by hypereosinophilia and swelling of the respiratory epithelium and often there were large sections of affected epithelium sloughing off an underlying basal epithelial layer. Regeneration was characterized by the presence of multiple layers of undifferentiated cells that lacked cilia in a region normally occupied by respiratory epithelium. Squamous metaplasia was characterized by the presence of regions in which the normal ciliated columnar epithelium had been replaced by squamous epithelium.

Changes involving the turbinates consisted of hyperostosis and deformity, reflecting post inflammation bony remodeling. These lesions were characterized by increased bony deposition (hyperostosis) and malformation. Occasional fusion of turbinates to the nasal septum and to each other was noted.

Lung: Suppurative inflammation was seen in the high dose males and females, characterized by acute accumulation of massive numbers of neutrophils and fibrin within alveolar spaces and bronchial and bronchiolar lumens. These lesions often were focally extensive over large portions of the affected lung lobes. There was occasionally necrosis of alveolar septa and bronchial and bronchiolar epithelium and focal or multifocal hemorrhage. The findings were considered consistent with aspiration pneumonia, though no foreign material was evident within the examined sections.

Heart: Epicardial inflammation was seen in both male and female rats, and a single case of pericardial inflammation was present in a male/female rat. Inflammation of the pericardium or epicardium occasionally extended into the underlying myocardium and was an extension of the inflammatory process in the lungs. Three incidences of mild myocardial necrosis occurred in the high dose males. Myocardial necrosis was characterized by multiple cardiomyocytes that were swollen and hypereosinophilic with a loss of cellular and nuclear detail. These cells often had an inflammatory infiltrate, composed of mostly neutrophils. This lesion was distinguished from cardiomyopathy due to the presence of multiple cardiomyocytes in the same acute stage of cellular death.

Bone marrow: Bone marrow hyperplasia, which was mainly composed of immature cells of granulocyte lineage was seen in the female rats.

Spleen: Lymphoid depletion, consisting of a decrease in white pulp (periarteriolar, follicular, or multizonal), was seen male and female rats.

2-year study in mice ${ }^{30}$

Nose: Nasal lesions included suppurative inflammation and foreign body, pigmentation hyperostosis, septum perforation, and turbinate atrophy.

Inflammation of the nasal cavity was characterized by accumulations of primarily neutrophils within the nasal lumen. In addition, variable numbers of neutrophils were undergoing transepithelial migration, and neutrophils were present in the underlying submucosal stroma. The foreign body material ranged from large pieces of plant material to hair shafts and other small refractile pieces of unidentifiable material. The foreign bodies were typically surrounded by 
neutrophils. Acellular greenish-brown debris was also present within the lumen of the nasal cavity in some animals. A small number of animals had a similar pigmented material accumulated in intraluminal macrophages. Hyperostosis was variably characterized by deposition of woven and lamellar bone within the nasal septum and along the ventral surface of the flat bones lining the dorsal portion of the nasal cavity. Some animals with expanded nasal septa had enlarged and irregularly shaped bone marrow spaces within the bony deposits. Perforation of the septum consisted of a discontinuation of the septum separating the right and left nasal passages. Turbinate atrophy varied from thinned and/ or slightly blunted nasoturbinates and maxilloturbinates to pronounced blunting and fusion of the turbinates.

In addition, nasopharyngeal duct degeneration and inflammation were observed. Nasopharyngeal duct degeneration was characterized by cell swelling and vacuolation of the respiratory epithelium lining the duct.

Olfactory epithelial lesions included respiratory metaplasia, fibrosis, and nerve atrophy. Necrosis of the olfactory epithelium also occurred in a few mice administered low and medium doses. Olfactory epithelium atrophy was also seen, but lower incidences were noted in the high dose groups of males and females, which may reflect a progression of some of the lesions into fibrosis of the olfactory epithelium.

Similarly, the few occurrences of necrosis of the olfactory epithelium probably represent that this lesion was fairly early in the process and was followed by atrophy, and subsequently fibrosis. Olfactory epithelium atrophy ranged from focally extensive lesions of decreased number and disorganization of the nuclear layers and loss of the lumenal eosinophilic border to extensive thinning and cellular loss of the olfactory epithelium. When becoming metaplastic, the olfactory epithelium was replaced by respiratory epithelium. In some animals with respiratory metaplasia of the olfactory epithelium, there were variable numbers of invaginations of the respiratory epithelium resembling glands within the subepithelial stroma. When fibrosis was present, the stroma underlying the affected olfactory epithelium was altered in that there was a loss of Bowman's glands, atrophy of the nerve bundles, and occasionally deposition of fibrous connective tissue. In some animals, generally those with more severe inflammation, the epithelium replacing the olfactory epithelium was composed of one or multiple layers of flattened squamoid epithelium that was most consistent with recently damaged/lost epithelium undergoing re-epithelialization. Necrosis of the olfactory epithelium was characterized by the presence of a segment or cluster of epithelial cells that were shrunken and hyper-eosinophilic with karyorrhexis and/or nuclear pyknosis with or without cell loss.

Respiratory epithelial lesions included necrosis, squamous metaplasia and hyperplasia. Necrosis of the respiratory epithelium was characterized by hypereosinophilia and cell swelling, and often there were large sections of affected epithelium sloughing off an underlying basal epithelial layer. Squamous metaplasia of the respiratory epithelium was characterized by replacement of the ciliated columnar epi- thelium by flattened squamous epithelium of variable thickness. Respiratory epithelium hyperplasia was characterized by increased numbers of cells piled up in multiple layers or forming folds and invaginations into the underlying lamina propria.

Lung: Inflammation was observed in male and female mice and was characterized primarily by massive infiltrates of neutrophils within alveolar spaces and extending into bronchioles and occasional bronchi. The lesions often were focally extensive over large portions of the affected lung lobes. There were small numbers of alveolar macrophages, and frequently there were large numbers of intracellular and extracellular bacteria admixed with the neutrophils.

Bone marrow: The incidence of hyperplasia was increased in treated groups compared to the control group. Bone marrow hyperplasia was mainly due to an increase in the myeloid cell population.

Mandibular lymph node: Lymphoid hyperplasia and plasma cell infiltration were observed. Plasma cell infiltration was characterized by increased plasma cells within the medullary cords. Lymphoid hyperplasia was characterized by enlarged follicles and lymphocyte proliferation in paracortical regions.

Liver: The incidences of hepatocellular adenoma or carcinoma was significantly less than those in the vehicle control groups. The incidences of multiple hepatocellular adenoma were also significantly decreased. There was also decreased incidence of clear cell foci and eosinophilic foci. In contrast, increased incidence of hematopoietic cell proliferation and inflammation were seen in the high dose male mice. Hematopoietic cell proliferation was composed of multiple small clusters of hematopoietic precursor cells scattered throughout the hepatic parenchyma. The precursor cells were predominantly of granulocytic origin. The hematopoietic cell proliferation seen in the liver was like the bone marrow hyperplasia and was a response to the continued inflammatory process occurring in the nasal cavities of the mice. Inflammation consisted of a variably mixed infiltrate of neutrophils and macrophages, with or without lymphocytes or plasma cells and was often associated with one or two individual necrotic hepatocytes.

Other organs: There was a decrease in the incidence of adrenal cortical hypertrophy pancreatic islet hyperplasia in males. Islet cell hyperplasia was characterized by an increase in the size of the pancreatic islets due to an increased number of normal looking islet cells. Affected islets did not compress the adjacent exocrine pancreatic tissue. In general, multiple islets were affected in each animal.

\section{Ma Huang (ephedra) in combination with guarana- derived caffeine}

The dietary supplements containing ephedra alkaloids are derived from the plant Ephedra sinica. Ephedrine and caffeine are the primary active components in dietary supplements that contain Ma Huang (ephedra) and guaranaderived caffeine. Ephedrine produces indirect stimulation of adrenoreceptors due to its ability to release norepinephrine 
and epinephrine from adrenergic nerve terminals. Thus, ephedrine has similar cardiovascular effects as epinephrine with longer-lasting effects.

The combination of ephedrine and caffeine has been linked to cardiotoxicity in rats and humans, including increased blood pressure, heart rate, and temperature, and interstitial hemorrhage. Additionally, degeneration of myofibers in the subendocardial myocardium of the ventricles and interventricular septum has been reported.

Seven- and 14-week-old male F344 rats were exposed by gavage to ephedrine $(25 \mathrm{mg} / \mathrm{kg})$ and caffeine $(30 \mathrm{mg} / \mathrm{kg})$ administered in combination for one or two days. Ephedrine dose selected was in the range of the high dose used in the two year-male-rat chronic study (National Toxicology Program, 1986) in which doses up to approximately $140 \mathrm{mg} / \mathrm{kg}$ were administered. The caffeine dosage was approximately equal to the amount of guarana-derived caffeine from a typical human ephedra-supplement dosage, approximately 12and 1.4-fold, respectively, above average human exposure, based on a $\mathrm{mg} / \mathrm{m}^{2}$ body surface-area comparison.

\section{Oral gavage administration of ephedrine and caffeine to 7- and 14-week-old male F344 rats $^{37}$}

Four-five hours after dosing, changes were observed in the interventricular septum of the 14-week-old treated rats. Less severe changes were also evident in the left and right ventricular walls. The changes consisted of severe interstitial hemorrhage in the subendocardial myocardium of the interventricular septa and the left ventricle. These changes were accompanied by degeneration of the myofibers, which also appeared vacuolated, hyalinized and with loss of striations. The nuclei were pyknotic (or completely lost) in some of the cells. The 7-week-old rats also showed ventricular hemorrhage, but the incidence rates and the severity were lower than in the 14-week-old rats.

Additional cardiac changes included multifocal, generalized loss of myofibers, which was associated with infiltration of macrophages, which were digesting fragments of nuclear chromatin and lysed fibers. The fragmented nuclei stained positive for anti-phospho-H2A.X, a marker for apoptosis. In the acutely affected animals, multifocal, intracytoplasmic myofibers stained positive for caspase-3, mostly in the interventricular septa. The caspase-3 staining in this case allowed the detection of myofibers with only morphological degenerative alterations, thus emphasizing the advantage of using this method for detecting the early stages of the apoptotic process. Barbeito-Lopez trichrome stain (BLTS) showed the presence of patchy yellow myofibers, thus indicating loss of striation and cytoplasmic homogenization of the fibers, further helping in the diagnosis of degeneration/necrosis of the myocardium.

More extensive foci of myocardial degeneration and necrosis were evident after two or three doses, mostly in subepicardial areas, and were accompanied by mixed inflammatory cell infiltration.
One bolus oral dose of Ma Huang (equivalent to 0 , $12.5,25$, or $50 \mathrm{mg} / \mathrm{kg}$ ephedrine) or ephedrine ( 0 , $6.25,12.5,25 \mathrm{mg} / \mathrm{kg}$ ) to male F344 rats with and without caffeine ${ }^{36}$

Ma Huang (equivalent to $0,12.5,25$, or $50 \mathrm{mg} / \mathrm{kg}$ ephedrine) or ephedrine $(0,6.25,12.5,25 \mathrm{mg} / \mathrm{kg})$ were administered as one bolus oral dose to male F344 rats with and without caffeine.

Ma Huang and ephedrine, with and without caffeine, induced hemorrhage, degeneration, and necrosis of the heart, mostly of minimal severity, in most of the moribund sacrificed animals (Fig. 18). The most common finding was myofiber necrosis. Hemorrhage was characterized by several foci of free red blood cells between bordering myocardial fibers. Degeneration was evident mostly in the interventricular septum and left ventricle, mostly in heart with associated necrosis, and consisted of scattered myocardial fibers with clear vacuolated cytoplasm. In addition, the sarcoplasm of treated animals had increased eosinophilia and variable hyalinization.

Necrosis of the myocardium was characterized by many scattered minute clusters of fragments of nuclear debris, with strong basophilic staining. The most involved region was the interventricular septum. The necrosis was probably an acute process since there was no associated inflammatory reaction. In some places, though, macrophages and eosinophilic material were evident in a clear space between adjacent fibers, suggesting focal loss of a pre-existing fiber. In some cases, an hyalinized and deeply eosinophilic myocardial fiber was found near a cluster of nuclear fragments, suggesting that it was in the process of coagulative necrosis. There was no accompanying inflammatory cell reaction. In contrast, significant inflammatory cell infiltrate was seen in a smaller number of larger foci. It was not possible to determine the specific cell that was undergoing nuclear fragmentation; however, these cells were probably either myocardial, inflammatory, endothelial, or interstitial cells.

Based on the pathology findings of these studies and the known properties of ephedrine and caffeine, it has been suggested that the cardiac toxicity is the result of catecholamine release after binding of ephedrine to $\alpha / \beta$ adrenergic membrane receptors, leading to calcium release and changes in electrical and contraction properties of the heart (Fig. 19) ${ }^{36}$. These effects result in myocardial ischemia, necrosis and apoptosis, which either culminates in hemorrhage and sudden death, or resolves with inflammation and fibrosis.

\section{Goldenseal10}

Goldenseal (Hydrastis canadensis), a member of the plant family Ranunculaceae, is a plant native to North America. The major alkaloids in goldenseal are berberine, hydrastine, and canadine.

It is a commonly used herbal product to treat ulcers, wounds, skin, mouth and eye infections, urinary disorders and gastrointestinal disturbances. Berberine is reported to 

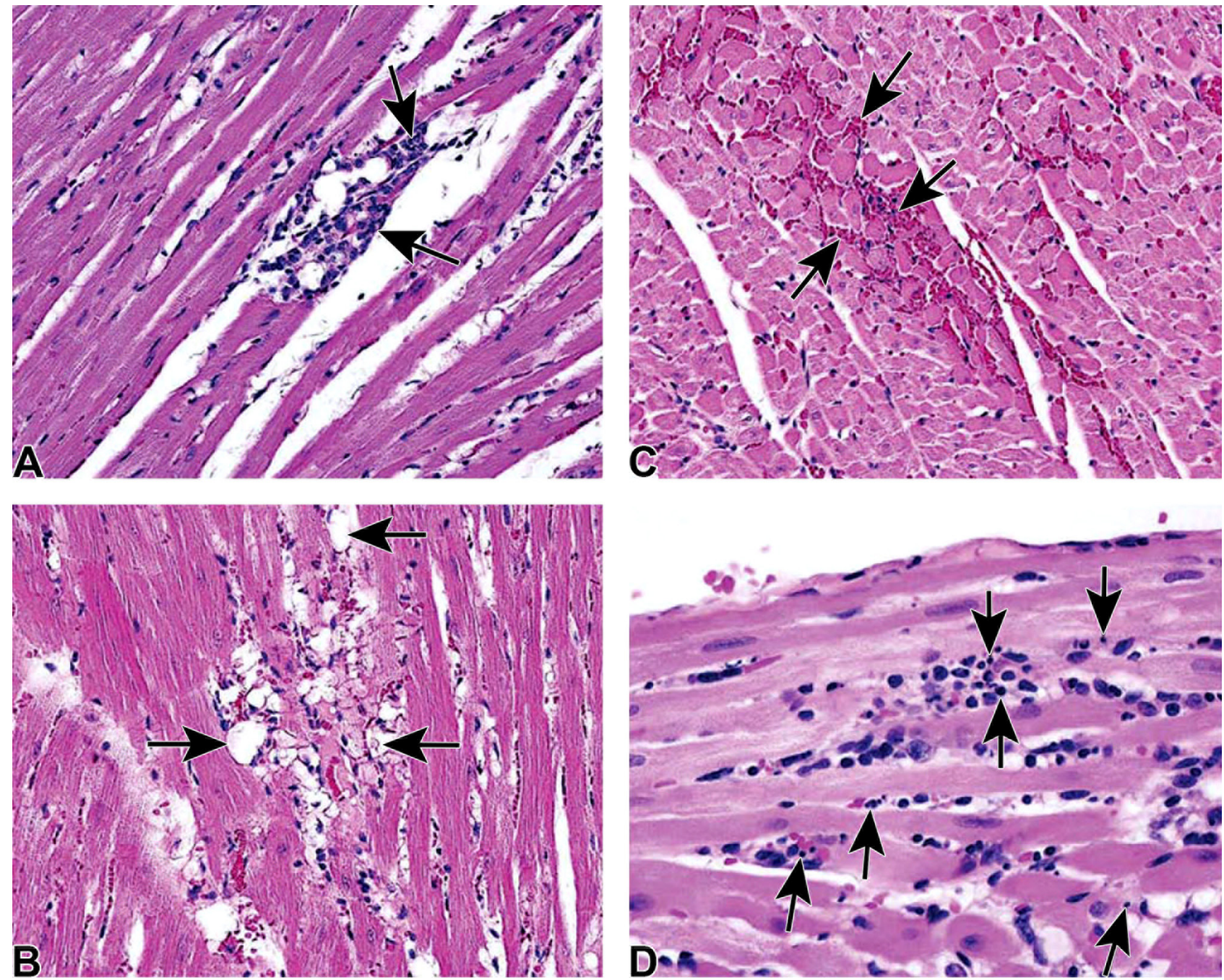

Fig. 18. Treatment-related cardiotoxic lesions. (A) Cardiomyopathy, minimal ( $25 \mathrm{mg} / \mathrm{kg}$ ephedrine and $7.25 \mathrm{mg} / \mathrm{kg}$ caffeine). This change is considered to be an incidental background change. Note (arrows) a single small focus of mononuclear cell (lymphocytes and histiocytes) infiltration, associated with variable myofiber degeneration, necrosis and loss. H\&E, 20×. (B) Degeneration, minimal (12.5 mg/kg ephedrine and $15 \mathrm{mg} / \mathrm{kg}$ caffeine), 20×. Note a focus of myocardial fibers with clear, vacuolated cytoplasm (arrows). H\&E, 20×. (C) Hemorrhage, minimal $(25 \mathrm{mg} / \mathrm{kg})$. Note small foci in which free red blood cells filling the spaces between adjacent myocardial fibers (arrows). H\&E, 20×. (D) Necrosis, minimal ( $25 \mathrm{mg} / \mathrm{kg}$ ephedrine and $30 \mathrm{mg} / \mathrm{kg}$ caffeine), 40×. Note the presence of numerous minute clusters of deeply basophilic fragments of nuclear debris (arrows), mixed with some macrophages. H\&E, 40×. Reproduced with permission from Dunnick et al., Toxicol Pathol. 2007; 35(5): 657-64.

have antifungal activity against Candida species, antimicrobial activity against Staphylococcus aureus, and also against various infectious agents in infectious diarrhea. Activity against cholera, amoebiasis, and Leishmania and Plasmodium were also reported. Berberine has also been reported to have anti-inflammatory, antiproliferative, cytostatic, and antioxidative effects.

In experimental studies, anti-tumor and anti-inflammatory activity, neuroprotective and immune-modulatory properties, and the ability to decrease plasma cholesterol were observed.

There are no 2-year rodent carcinogenicity studies of goldenseal, berberine, or hydrastine reported in the literature. However, berberine showed cytotoxic/antiproliferative effects in various cancer cell lines in some studies, while other studies showed no inhibition of cell growth.

No reports on the genotoxicity of goldenseal were found in the literature.

The mechanism of actions is believed to involve inhibition of enzymes such as CYPs and topoisomerases, and/or effects on cell signaling, receptors, and transporters.

Groups of five male and five female rats and mice were fed diets containing $0,1,560,3,121,6,250,12,500,25,000$, or $50,000 \mathrm{ppm}$ goldenseal root powder for 15 days.

Groups of 50 male and 50 female rats and mice were fed diets containing $0,3,000,9,000$, or 25,000 ppm goldenseal root powder for 105 to 106 weeks. 


\section{Proposed Mechanism of Ephedrine/Caffeine Heart Toxicity}

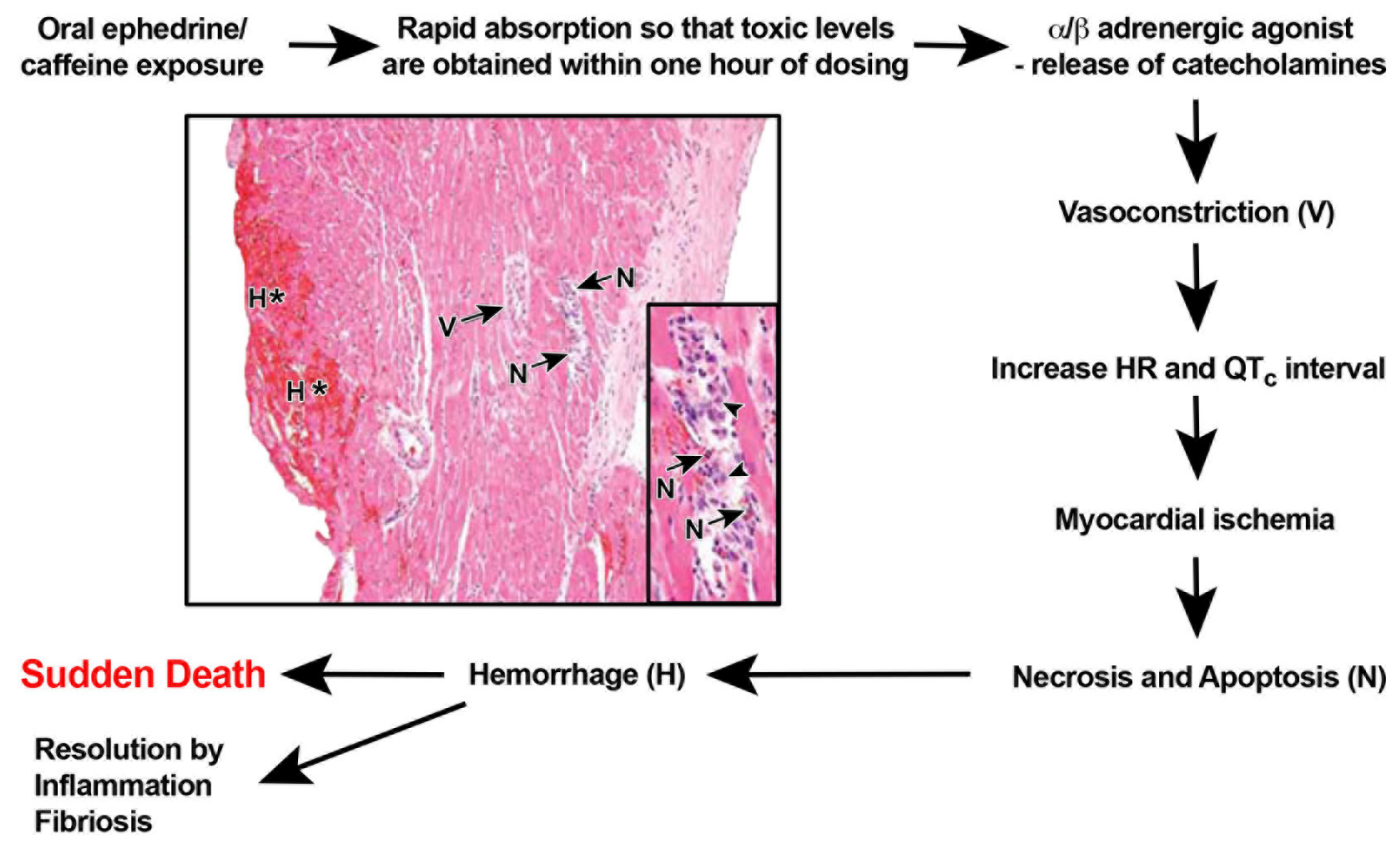

Fig. 19. Proposed mechanism of ephedrine cardiotoxicity (cardiotoxicity at $25 \mathrm{mg} / \mathrm{kg}$ ephedrine and $30 \mathrm{mg} / \mathrm{kg}$ caffeine is depicted in figure). Reproduced with permission from Dunnick et al., Toxicol Pathol. 2007; 35(5): 657-64.

\section{Pathology findings}

2-week study in rats ${ }^{10}$

The only finding was minimal to moderate hepatocellular hypertrophy, characterized by enlargement of the hepatocytes in the centrilobular areas of the lobules.

3-month study in rats ${ }^{10}$

The only involved organ was the liver. Findings included hepatocyte hypertrophy, characterized by enlargement of the hepatocytes in the centrilobular areas and extending to the midzonal area; and cytoplasmic vacuolization of hepatocytes, consisting of either solitary or multiple vacuoles within the cytoplasm of hepatocytes. These vacuoles appeared to have contained fat and were characterized by clear spaces that often displaced the nucleus to the periphery of the cell.

\section{2-year study in rats ${ }^{42}$}

Liver: The liver was the main target organ. Findings included an increase in the incidence of hepatocellular adenoma and hepatocellular adenoma or carcinoma (combined) in treated groups when compared to the concurrent control group. The main characteristics of the hepatocellular adenoma included solid sheets of large eosinophilic, often vacuolated cells, without normal hepatic lobular architecture. The tumor compressed the adjacent nonneoplastic liver parenchyma. Hepatocellular carcinomas were characterized by a large mass of large, pleomorphic, significantly vacuolated cells that formed thickened trabeculae.
Non-neoplastic lesions in the liver included hepatocellular degeneration, hepatocellular hypertrophy, and eosinophilic foci. The eosinophilic foci were isolated areas composed of enlarged hepatocytes with homogenous or finely granular, eosinophilic cytoplasm. This enlargement resulted in some compression of neighboring parenchyma. Hepatocyte hypertrophy was characterized by lobular areas of minimally to moderately enlarged hepatocytes with increased amounts of eosinophilic cytoplasm accompanied by various degrees of vacuolization. The main areas of hepatocellular hypertrophy were the centrilobular and midzonal regions, with relative sparing of the periportal areas. However, in the more severe cases, the entire parenchyma was involved. Hepatocellular degeneration was characterized by large hepatocytes with either numerous small, discrete, clear vacuoles or finely granular, pale, slightly eosinophilic cytoplasm. The degeneration was sometimes accompanied by individual cell necrosis.

Spleen: The incidence of hematopoietic cell proliferation was increased in treated male rats when compared to the concurrent control group, and was characterized by an increase in small, deeply basophilic erythroid cells and less commonly by large immature myeloid cells within the red pulp.

Heart: Goldenseal treatment resulted in decreased incidence of cardiomyopathy. Cardiomyopathy was characterized by localized regions of loss of myocytes, coagulative 
necrosis and mineralization of small numbers of individual myocytes, limited inflammatory cell infiltrates composed of a few macrophages and lymphocytes with occasional neutrophils, and various degrees of fibrosis.

Lungs: Goldenseal treatment also resulted in a decrease in the incidences of chronic lung inflammation.

Nose: There was a decrease the in the incidence of chronic nasal inflammation, which was composed of a variety of cells, including macrophages, neutrophils and lymphocytes. The cell infiltrate was accompanied by fibrosis in the submucosal tissues.

2-week study in mice ${ }^{10}$

Minimal hypertrophy of centrilobular hepatocytes was observed in both males and females.

\section{3-month study in mice ${ }^{10}$}

There was increased incidence of hepatocyte hypertrophy, which was consistent with increased liver weights.

\section{2-year study in mice 42}

Liver: There were increased incidences of hepatocellular adenoma in treated groups of male mice when compared to the concurrent control group. Increased incidences of multiple hepatocellular adenoma in groups treated with mid-high doses was observed. The features were similar to those reported in $\mathrm{B} 6 \mathrm{C} 3 \mathrm{~F} 1$ mice. They were characterized by distinct masses that compressed the adjacent normal parenchyma, sometimes projecting above the surface of the liver. They were composed of pleomorphic hepatocytes that were usually normal in size. Neoplastic hepatocytes seen in the adenomas commonly resembled those seen in eosinophilic foci, but clear, basophilic, and vacuolated hepatocytes were also present. Plates of neoplastic hepatocytes intersected the surrounding normal hepatocytes, disrupting the normal lobular architecture. This was accompanied by disappearance of the normal arrangement of central veins and portal triads. Some of the adenomas had atypical appearance and size, having no demarcated borders and composed of variable numbers of eosinophilic, basophilic, clear, or vacuolated hepatocytes.

There was an increased incidence of hepatoblastoma, which showed a positive trend and a marginal, but not statistically significant increase in the high dose males. Hepatoblastomas are malignant neoplasms, considered to be a primitive form of hepatocellular carcinoma. In the affected mice, the hepatoblastomas were commonly well demarcated from the surrounding tissue, and consisted of clusters, nests, or sheets of spindle-shaped cells that had little amount of basophilic cytoplasm and round to oval hyperchromatic nuclei. Sometimes the hepatoblastomas appeared within a hepatocellular carcinoma and at other times arose directly from the liver parenchyma.

There was also an increase in the incidence of eosinophilic and mixed cell focus in the treated male groups compared to the control group. The eosinophilic foci were small to moderately large lesions composed of hepatocytes that had homogenous or finely granular, eosinophilic cytoplasm. The hepatocytes were assembled in normal lobular patterns in which hepatic cords fused with the adjacent normal hepatocytes. There was almost no compression of the surrounding normal hepatocytes, except in several larger foci. The mixed cell foci were usually larger than other types of foci and consisted of a mixture of eosinophilic or basophilic cells and clear cells.

In summary, in male mice, there was evidence for a carcinogenic effect in male mice based on the increase in hepatoblastomas and adenomas, particularly multiples. There was no statistically significant carcinogenic effect in female mice. However, the incidence of hepatocellular adenoma in all treated groups was above the range of that seen in the historical controls.

\section{Aloe Vera ${ }^{43}$}

The Aloe barbadensis Miller (Aloe vera Linné) plant, referred to as Aloe vera, has green fleshy leaves of 3 identifiable layers, which include the rough, thick cuticle, rind tissue underneath, and the water parenchyma beneath the rind tissue. The aloe gel, extracted from the inner pulp, is the mucilaginous clear component of the plant. Decolorized aloe vera is also known as whole leaf aloe vera since it undergoes activated carbon adsorption to remove the phenolic components of aloe latex.

Aloe vera is a popular, widely used dermatologic agent for skincare. Multiple clinical trials were performed to examine the effects of Aloe vera, which also included comparison with Vaseline ${ }^{\mathrm{TM}}$ gauze treatment in patients with partial thickness burn wounds showing enhanced angiogenesis, collagen formation and shorter healing process. It was also examined in radiation induced dermatitis and psoriasis. Several studies investigated the ability of aloe vera extract in preventing the suppression of delayed type hypersensitivity and contact dermatitis by ultraviolet (UV) irradiation and its influence on lymphocyte function. Aloe vera significantly reduced leukocyte adhesion and serum levels and tumor necrosis factor (TNF) and interleukin (IL)-6 levels.

Significant phototoxicity was observed with aloe-emodin to both UVA and visible light, suggesting reactive oxygen species generation.

No studies examined the carcinogenicity of aloe vera plant extracts in experimental animals or humans.

The NTP conducted a study on Groups of four male and four female $\mathrm{F} 344 / \mathrm{N}$ rats and female $\mathrm{B} 6 \mathrm{C} 3 \mathrm{~F} 1$ mice were administered Aloe vera gel, Aloe vera nondecolorized whole leaf, or Aloe vera decolorized whole leaf extracts in drinking water at concentrations of $0,0.5 \%, 1.0 \%, 1.5 \%, 2.0 \%$, or $3.0 \%$ (wt/wt) for a period of 14 days.

Groups of 12 male and 12 female F344/N rats were administered Aloe vera nondecolorized whole leaf extract in drinking water at concentrations of $0,1 \%, 2 \%$, or $3 \%(\mathrm{wt} / \mathrm{wt})$ for a period of 13 weeks. Groups of 12 male and 12 female B6C3F1 mice were administered Aloe vera nondecolorized whole leaf extract in drinking water at concentrations of 0 , $1 \%, 2 \%$, or $3 \%(\mathrm{wt} / \mathrm{wt})$ for a period of 13 weeks. The bulk Aloe vera nondecolorized whole leaf extract test material had a malic acid content of 170.7 to $192.9 \mathrm{mg} / \mathrm{g}$ and an aloin 
A content of 12.6 to $14.4 \mathrm{mg} / \mathrm{g}$.

Groups of 48 male and 48 female F344/N rats were administered Aloe vera nondecolorized whole leaf extract at concentrations of $0,0.5 \%, 1.0 \%$, or $1.5 \%(\mathrm{wt} / \mathrm{wt})$ in drinking water. Groups of 48 male and 48 female B6C3F1 mice were administered Aloe vera nondecolorized whole leaf extract at concentrations of $0,1.0 \%, 2.0 \%$, or $3.0 \%$ (wt/wt) in drinking water for 2 years. The bulk Aloe vera nondecolorized whole leaf extract test material had a malic acid content of 186 to $203 \mathrm{mg} / \mathrm{g}$ and an aloin A content of 5.7 to $7.2 \mathrm{mg} / \mathrm{g}$.

\section{Pathology findings}

2-week study in rats ${ }^{43}$

There was no increased incidence of neoplasms. Nonneoplastic changes related to the administration of the Aloe vera whole leaf extract were found mainly in the large intestine, where goblet cell hyperplasia was detected. Additional findings were lymphoid hyperplasia of the mesenteric lymph nodes and goblet cell hyperplasia of the cecum and colon.

\section{2-year study in rats ${ }^{43}$}

There were increased incidences of adenomas and carcinomas of the large intestine in both male and female treated groups compared to the concurrent control group(s). Adenomas were observed as pedunculated nodules, polypoid masses that protruded into the intestinal lumen, or sessile lesions that caused thickening of the intestinal wall. Epithelial cells within adenomas were well differentiated and resembled cells in adjacent hyperplastic mucosal epithelium but formed distorted, glandular arrangements often with mild compression of adjacent mucosa (Fig. 20A). Diagnosis of carcinoma was based on invasion of the stroma of the stalk into the submucosa and/or muscularis of the intestinal wall and anaplastic changes in the neoplastic epithelial cells, including hyperchromatic staining and distortion of cellular size and shape (Fig. 20B).

Molecular testing of the colon neoplastic lesions in the aloe vera-treated rats revealed mutations in the Kras and Ctnnb1 genes ${ }^{26}$. No mutations were found in Tp53. Molecular pathways important in human colorectal cancers such as MAPK, WNT, and TGF-b signaling were also modified. These changes are similar in part to the changes observed in human colorectal cancers.

Non-neoplastic findings were observed mainly in the large intestine and associated mesenteric lymph nodes. In male rats, mucosal hyperplasia of the large intestine was a frequent finding, and the severities were greater, and the incidences higher, in the ascending and transverse colon-the same sites that had increased incidences of neoplasms. Additional findings included degeneration and hyperplasia of mesenteric lymph nodes; hyperplasia of the glandular stomach mucosa and the mucosa of the small intestine; and cecal dilatation. In female rats, in addition to mucosal hyperplasia of the colon, similar changes were found in the mucosa of the glandular stomach, forestomach, small intestine, and rectum. Additional changes in female rats included cecal dilatation, degeneration and atrophy of mesenteric lymph
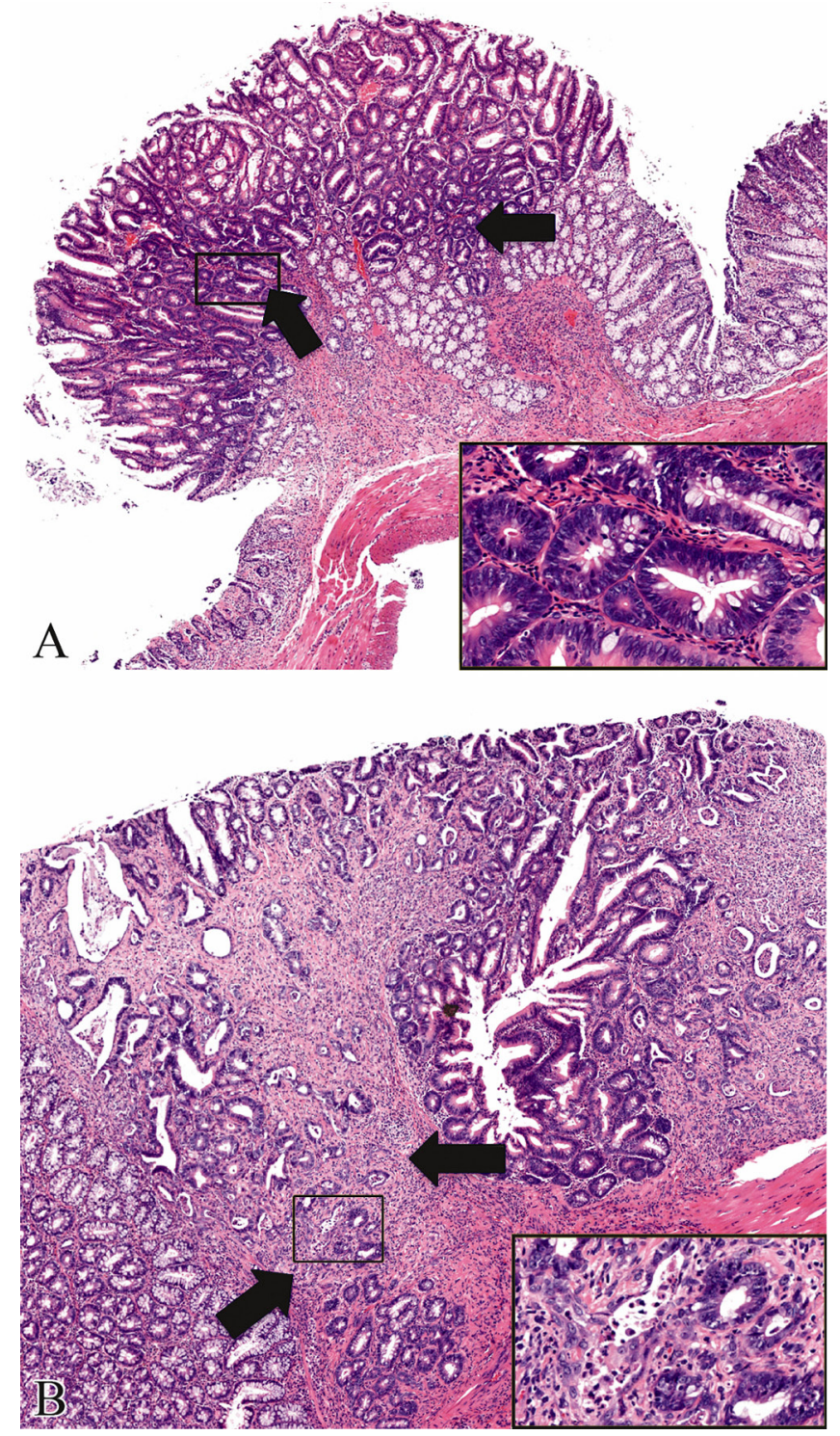

Fig. 20. Tumor sections from F344 rats exposed to Aloe vera nondecolorized whole leaf extract in drinking water, ad libitum, for two years. (A) Adenoma $(50 \times)$. The exophytic mass with dysplastic hyperchromatic cells (arrows and inset box) was limited to the mucosa without evidence of invasion into the muscularis mucosa. (B) Carcinoma $(60 \times)$. Note the neoplastic cells invading past the muscularis mucosa (arrows) and the fibroplasia surrounding the neoplastic cells (inset box). Reproduced with permission from Pandiri et al., Toxicol Pathol. 2011; 39(7): 1065-74.

nodes, and forestomach inflammation.

13-week study in mice ${ }^{43}$

Nonneoplastic changes primarily occurred in the large intestine and resulted in increased incidences and severities of goblet cell hyperplasia in male and female treated groups when compared to the control group(s).

2-year study in mice ${ }^{43}$

There were no significant changes in the incidences of neoplastic lesions in male mice. In female mice, a significant 
dose-dependent decreasing trend in the incidence of anterior pituitary gland adenoma was observed.

Treatment related nonneoplastic lesions appeared primarily in the colon of mice. These included significant dose dependent increasing trends in the incidences of goblet cell hyperplasia, associated with cellular infiltration of the mesenteric lymph nodes. Dose-related increasing levels of hyaline droplets (hyaline degeneration) of the nose were also observed, consisting of accumulation of homogeneous eosinophilic material within the cytoplasm of epithelial cells.

1 -year photocarcinogenesis study in mice ${ }^{43}$

Groups of 36 male and 36 female Crl:SKH-1 (hr -/hr -) hairless mice received topical applications of control cream or creams containing $3 \%$ or $6 \%(\mathrm{w} / \mathrm{w})$ aloe gel, whole leaf, or decolorized whole leaf or 7.46 or $74.6 \mu \mathrm{g} / \mathrm{g}$ aloe-emodin to the dorsal skin region each weekday morning. The mice were irradiated with SSL emitted from filtered $6 \mathrm{~kW}$ xenon arc lamps each weekday afternoon. The topical applications of creams and irradiance exposures were conducted 5 days per week for a period of 40 weeks. A recovery/observation period of 12 weeks followed the 40 -week treatment/exposure period. Additional groups of 36 male and 36 female mice received no cream and were exposed to $0.00,6.85$, 13.70 , or $20.55 \mathrm{~mJ} \cdot \mathrm{CIE} / \mathrm{cm}^{2} \mathrm{SSL}$ per day.

The multiplicities of the combination of all squamous cell neoplasms (papilloma, carcinoma in situ, and carcinoma) were significantly increased in aloe vera and aloeemodin treated mice in pairwise comparisons with control cream animals, suggesting a photococarcinogenic-enhancing effect induced by each of the compounds.

\section{Riddelliine $^{12}$}

Riddelliine is a pyrrolizidine alkaloid found in plants of the genera Crotalaria, Amsinckia, and Sencio that grow in Western United States.

The pyrrolizidine alkaloids (plant, crude extracts of the plant, or the alkaloids) were administered to rats via varying routes (gavage, drinking water, subcutaneous, and intraperitoneal) to study their carcinogenicity. Studies reported that liver tumors, including hepatic angiosarcoma, hepatic adenoma, and hepatocellular carcinoma were the main pathological findings. Hemangioendothelial sarcomas were also induced. When administered subcutaneously, rats developed rhabdomyosarcomas at the site of injection. Tumors in the liver, lungs, intestines, and other organs were also induced when administered intraperitoneally.

According to the genotoxicity data, riddelliine was mutagenic in Salmonella typhimurium strain TA 100 with S9 activation and induced sister chromatid exchanges in Chinese hamster ovary $(\mathrm{CHO})$ cells.

Hydrolysis and N-oxidation seem to be the main pathways for metabolism of pyrrolizidine alkaloids.

The studies performed included 2-week and 13-week studies with 14 -week recovery in $\mathrm{F} 344 / \mathrm{N}$ rats and $\mathrm{B} 6 \mathrm{C} 3 \mathrm{~F}_{1}$ mice In the 2-week studies, groups of five male and female rats and five mice were administered riddelliine in $0.1 \mathrm{M}$ phosphate buffer by gavage at dose levels of $0,0.33,1.0,3.3$, 10 , and $25 \mathrm{mg} / \mathrm{kg}$ of body weight.

The high dose selected for the 13-week studies was 10 $\mathrm{mg} / \mathrm{kg}$ for rats and $25 \mathrm{mg} / \mathrm{kg}$ for mice, based on the results of the 2-week studies. In the 13-week studies, groups of 20 rats and 20 mice of both sexes were administered riddelliine in $0.1 \mathrm{M}$ phosphate buffer by gavage. Dose levels for rats were $0,0.1,0.33,1.0,3.3$, or $10 \mathrm{mg} / \mathrm{kg}$ body weight; dose volumes of $5 \mathrm{~mL} / \mathrm{kg}$ body weight were based on individual rat body weights taken weekly. Dose levels for mice were 0 , $0.33,1.0,3.3,10$, or $25 \mathrm{mg} / \mathrm{kg}$; dose volumes of $10 \mathrm{~mL} / \mathrm{kg}$ body weight were based on individual body weights taken weekly.

Groups of 50 animals per species per sex were administered riddelliine in $0.1 \mathrm{M}$ phosphate buffer by gavage five times a week for 105 weeks at doses 0 or $1.0 \mathrm{mg} / \mathrm{kg}$ body weight in male rats; $0,0.01,0.033,0.1,0.33$, or $1.0 \mathrm{mg} / \mathrm{kg}$ female rats; $0,0.1,0.3$, or $1.0,3.0 \mathrm{mg} / \mathrm{kg}$ in male mice; and 0 or $3.0 \mathrm{mg} / \mathrm{kg}$ in female mice.

\section{Pathology findings}

2-week study in rat ${ }^{12}$

The most significant histopathologic effects of riddelliine treatment were in the liver. Additional histopathologic effects of riddelliine administration were also found in the lung and spleen of both sexes and in the pancreas of males.

Liver: Male rats had dose-related hemorrhagic centrilobular hepatic necrosis, hepatocytic karyomegaly and cytologic alterations, consisting of karyomegaly and increased amounts of homogeneous to granular eosinophilic cytoplasm.

Other organs: In the lung, the main findings were focal hemorrhage and/or edema, generally perivascular in location. In the spleen, there was increased incidences of hematopoietic cell proliferation in treated animals when compared to the control groups. Separation of pancreatic lobules by interstitial hemorrhage and edema was also present. In multiple lymph nodes, congestion and associated erythrophagocytosis by medullary histiocytes were observed. In general, female rats exhibited fewer and less severe lesions than identically treated male rats.

13 -week study in rats ${ }^{12}$

The most significant treatment-related histopathologic lesions occurred in the liver, with the main findings being necrosis and cytologic change of hepatocytes, proliferative lesions of hepatocytes, and bile duct hyperplasia. In males, necrosis was more severe than in the females, and consisted of coagulative changes or drop-out of hepatocytes, mainly in centrilobular areas, with associated congestion and/or hemorrhage. The remaining parenchymal cells had cytologic alterations consisting of karyomegaly and increased amounts of eosinophilic, glassy cytoplasm. The cellular enlargement led to disruption of the hepatic cord architecture. Scattered hepatocytes had distended, vacuolated cytoplasm. Additional findings included hyperplasia of bile ductules, usually in the periportal area and extending into surrounding parenchyma, and mixed inflammatory cell infiltration 
that included numerous macrophages containing pigment (hemosiderin). After a 14-week recovery period, hepatocyte karyomegaly, cytomegaly, and cytoplasmic vacuolization persisted. Additionally, the incidence of bile duct hyperplasia was increased in female rats, and foci of cytologic changes or hyperplastic hepatocytes were observed. Adenomas of the liver occurred in a few female rats, and proliferative hepatocellular lesions diagnosed as foci of cellular alteration or focal nodular hyperplasia were also found in female rats.

Aggregates of intravascular macrophages were found in the kidneys and lungs, which appeared free in the vessel lumen or closely adherent to the underlying endothelium. In the kidneys, they were most abundant in the large veins of the renal cortex and in appeared in variably sized vessels in the lung.

Additional findings included mild to moderate hematopoietic cell proliferation in the red pulp of the spleen, together with lymphoid depletion of the white pulp. In high-dose males, there was a mild increase in intracellular pigment (hemosiderin) within macrophages. Bone marrow hyperplasia, involving both myeloid and erythroid components, was found in male and female rats.

In the lymph nodes, moderate to marked congestion, erythrophagocytosis, and accumulation of hemosiderinladen macrophages were observed in both sexes. In many cases, red blood cells filled the subcapsular and medullary sinuses where they were frequently phagocytosed within macrophages. Hemorrhagic lesions of the heart were also evident in males and females, which were in the subepicardial myocardium of the ventricles and were characterized by the separation of myofibers by the accumulation of red blood cells.

Interstitial edema of the pancreas, which was characterized by widening of the interstitial spaces, was found in both sexes of rats in the high dose groups and persisted into the recovery period.

In the kidney, minimal to moderate mineralization was found in the renal tubules of all males in the high-dose group. Additionally, hydropic degeneration of the transitional epithelium of the renal pelvis and hemosiderin accumulation in the tubule were observed primarily in high-dose males. Luminal, mucosal, or submucosal hemorrhage at various locations along the gastrointestinal tract occurred frequently in high-dose male rats, and submucosal edema was a frequent finding in the lower intestines of these animals as well.

2-year study in rats ${ }^{44}$

The main finding was a high incidence of hemangiosarcomas in the livers, which were the cause of death in many animals due to necrosis and hemorrhage of the tumors (Fig. 21). The hemangiosarcomas varied in size, but were mostly between 0.5 to $1 \mathrm{~cm}$. The metastases were in the lungs in half of the cases. Additional locations include the mediastinal lymph node, mesentery, and spleen. Primary hemangiosarcoma of the lung was found in one animal.

Higher incidences of hepatocellular adenoma or carcinoma were found in treated male and female rats. The hepatocellular adenomas were characterized by proliferations of hepatocytes that led to compression of the adjacent tissue. There was also loss of the normal architecture of the hepatic lobules. Additional liver findings attributed to treatment included diffuse hepatocytic-regenerative hyperplasia ${ }^{45}$ (evidence of prior or ongoing hepatocellular damage; normal lobular architecture is present, albeit distorted), hepatocytic cytomegaly, focal necrosis, eosinophilic focus, clear cell focus and bile duct hyperplasia.

Mononuclear cell leukemia was also observed in all organs in both male and female rats treated with $1.0 \mathrm{mg} / \mathrm{kg}$ per day despite the significant early mortality from liver toxicity in these animals.

Additional non-liver findings included renal tubule necrosis and transitional epithelial hyperplasia in the kidney.

To better understand the pathogenesis of hemangiosarcoma development in riddelliine-treated animals, F344/N rats were treated short-term with high doses of riddelliine ${ }^{46}$. This treatment led to high numbers of apoptotic and $S$-phase nuclei in endothelial cells and hepatocytes. Additional doses of riddelliine resulted in decreased mitosis, fatty degeneration, and increased hypertrophy of hepatocytes. Immunohistochemical evaluation revealed higher expression of VEGF immunopositivity. Endothelial cells showed cytomegaly, karyomegaly, and decreased apoptosis with more p53 positivity and S phase nuclei. Based on these findings, it was concluded that hemangiosarcoma development was the result of endothelial adduct formation, apoptosis, and mutation and proliferation of endothelial cells. The arrest of endothelial cells in the $\mathrm{S}$ phase, leading to the observed karyo- and cytomegaly, may have resulted in hypoxia of hepatocytes and VEGF induction.

2-week study in mice ${ }^{12}$

The only histopathologic finding was cytomegaly of hepatocytes, characterized by enlargement of the centrilobular cells of the liver.

13-week study in mice ${ }^{12}$

Histopathological changes were noted in the liver and forestomach. Liver lesions included centrilobular cytomegaly, characterized by large amounts of pale-staining, finely granular cytoplasm in the hepatocytes. Hyperplasia of the stratified squamous epithelium of the forestomach was also observed. This hyperplasia was characterized by mild, focal lesion of increased number of cell layers leading to increased epithelial thickness.

2-year study in mice ${ }^{44}$

There were increased incidences of hemangiosarcoma in the liver, and some of the animals also showed endothelial cell hyperplasia, considered to be a preneoplastic alteration. Some animals had hemangiosarcomas in the lungs. Focal hemorrhage sometimes accompanied the hemangiosarcomas. Additional lesions in the liver included increased incidence of hepatocyte cytomegaly and karyomegaly, bile duct hyperplasia, centrilobular necrosis of hepatocytes, focal hepatocyte coagulative necrosis, and mixed cell cellular infiltration.

Additional affected organs included the lungs, where alveolar/bronchiolar adenoma and adenoma or carcinoma 


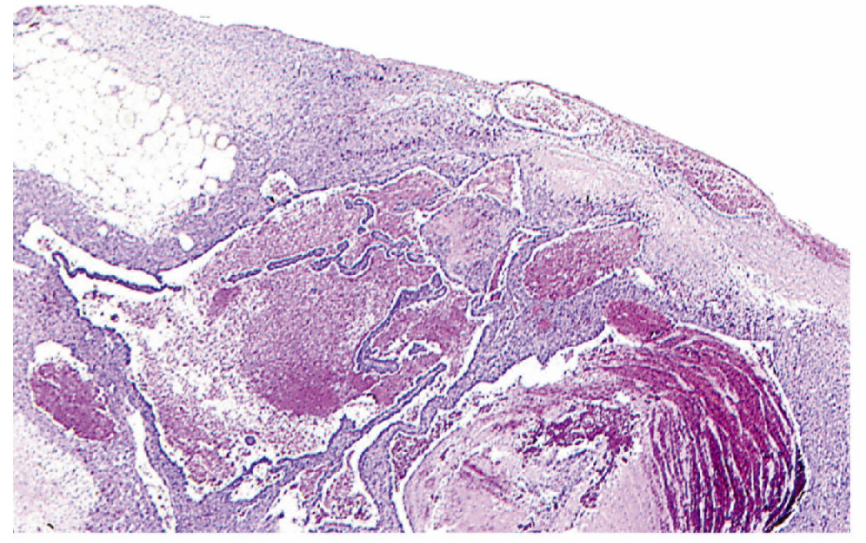

A

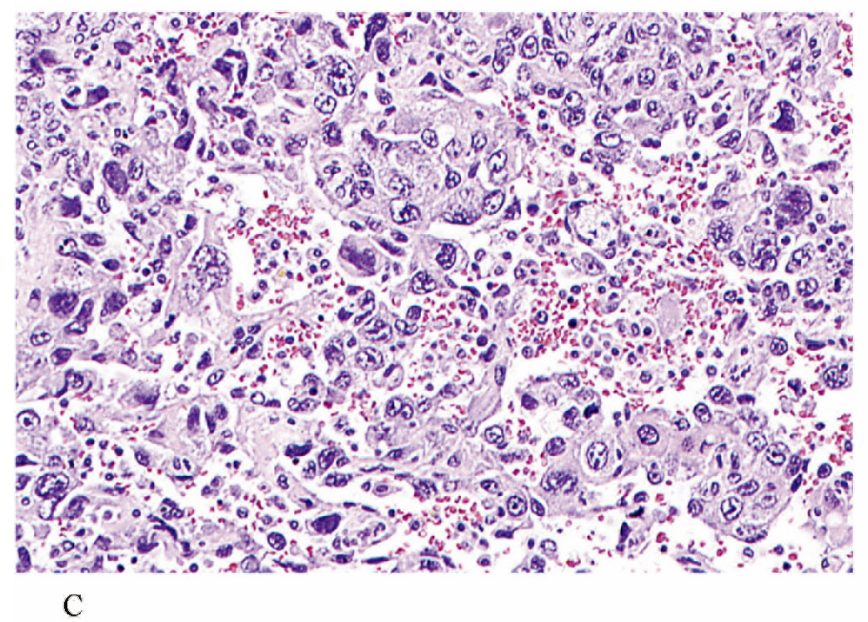

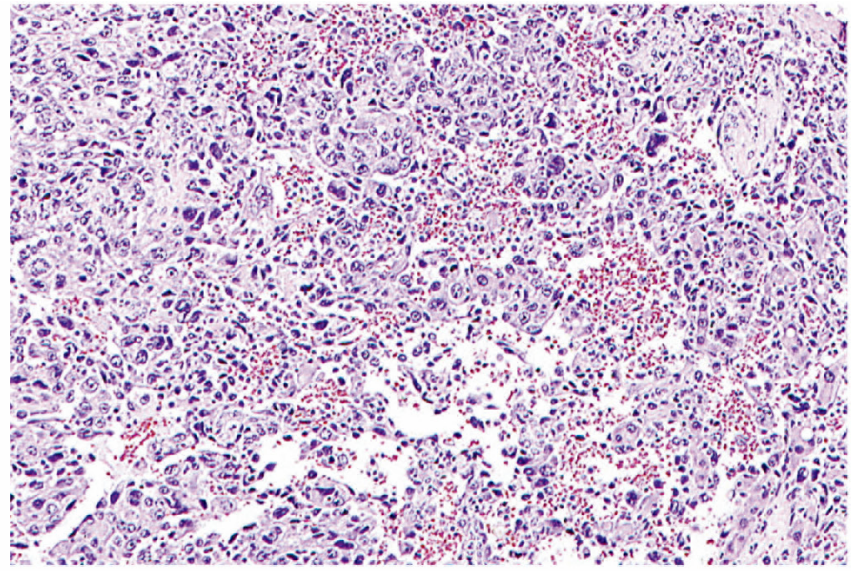

$\mathrm{B}$

Fig. 21. (A) Liver hemangiosarcoma in a female rat administered $1.0 \mathrm{mg} / \mathrm{kg}$ per day riddelliine by gavage for 2 years. Multiple hemorrhagic cavities are surrounded by a variably sized rim of neoplastic tissue (H\&E, low magnification). (B and C) Liver hemangiosarcoma in a male rat administered $1.0 \mathrm{mg} / \mathrm{kg}$ per day riddelliine in the 2-year gavage study. Irregular vascular spaces lined by pleomorphic endothelial cells (H\&E, B and C - Medium and high magnifications respectively of photo A). Reproduced with permission from Chan et al., Toxicol Lett. 2003, 144(3): 295-311.

(combined) were seen in higher numbers in treated females when compared to the concurrent control groups. The incidence of alveolar epithelial hyperplasia was also increased in treated female mice compared to controls. Several lesions were also observed in the kidneys of both sexes of treated animals, including increased severity of common, age-related nephropathy, which was also the cause of death of many female mice. Additional treated-related findings in the kidneys included glomerulosclerosis, renal tubule karyomegaly, renal tubule dilatation, and accumulation of renal tubular hyaline droplet and granular, brown pigment, which appeared to be correlated with the observed nephropathy.

Chronic inflammation of the arteries was observed in many of the examined organs of dosed females, including mainly the kidney, uterus, ovary, small (duodenum) and large (cecum) intestines, spleen and mesentery. Sporadic cases of chronic inflammation of the arteries were also observed in the duodenum, heart, kidney, and spleen of dosed males.

\section{Pulgeone $^{13}$}

$[R-(+)$-pulegone] is a colorless, oily liquid which has an odor between peppermint and camphor.

Pulegone is found naturally in food products but may also be produced synthetically. Essential oils containing pulegone are derived from many plant species, including Hedeoma pulegioides (American pennyroyal), species of the genus Bystropogon (evergreen shrubs), and species of the genus Mentha [e.g., European pennyroyal (M. pulegium), cornmint, Biblical mint]. Pulegone-containing essential oils are used for flavoring foods, drinks and dental products as well as a fragrance agent. It has been also used as a herbal remedy as an abortifacient.

Three major pathways are believed to be involved in the mechanism of pulegone: 1) hydroxylation to monohydroxylated pulegones, followed by conjugation of glucuronic acid or with glutathione and further metabolism; 2) reduction of the carbon-carbon double bond leading to menthofuran formation; and 3) formation of pipertienone after 5-hydroxyl- 
ation, followed by dehydration.

No data were found in the literature on the carcinogenicity of pulegone in experimental animals or humans.

In the NTP 2-week studies, groups of five male and five female rats and mice were administered pulegone $/ \mathrm{kg}$ body weight in corn oil by gavage, 5 days per week for 16 days at doses of $0,37.5,75,150,300$, or $600 \mathrm{mg}$ in rats and $0,18.75$, $37.5,75,150$, or $300 \mathrm{mg}$.

In the 3-month studies, groups of 10 male and $10 \mathrm{fe}-$ male rats and mice were administered $0,9.375,18.75,37.5$, 75 , or $150 \mathrm{mg}$ pulegone $/ \mathrm{kg}$ body weight in corn oil by gavage, 5 days per week for 14 weeks.

In the 2-year studies, groups of 50 male and 50 female rats and mice were administered 0, 18.75 (male rats only), $37.5,75$, or 150 (mice and female rats only) mg pulegone/ $\mathrm{kg}$ body weight in corn oil by gavage, 5 days per week for up to 104-105 weeks oil by gavage, 5 days per week for up to 104 weeks.

\section{Pathology findings}

2-week study in rats ${ }^{13}$

Treatment-related findings were found in the livers of the male and female rats and included necrosis and cytoplasmic vacuolization. Hepatocellular zonal necrosis was observed, involving particular zones of the acinus. Acinar zones 1, 2, and 3 correspond to the periportal, mid-, and pericentral zones of the lobule, respectively ${ }^{47}$. Hepatocellular necrosis was centrilobular in distribution, yet it sometimes extended into zone 2 to bridge lobules. Centrilobular and midzonal necrosis were sometimes accompanied by hemorrhage. Hepatocellular vacuolization was characterized by swollen hepatocytes with fine vacuolated cytoplasm, often located at the peripheral margin of regions of necrosis.

3 -month study in rats ${ }^{13}$

Pathological findings were found in the kidneys of the male and female rats. They included hyaline glomerulopathy, that was diagnosed when numerous, small, round, eosinophilic globules were found within the glomerular mesangium. The mesangium was usually expanded in the areas containing the globules. The globules were frequently clustered tightly together and located adjacent to capillary loops and were suspected to be protein globules based on their morphology. The globules stained weakly with Periodic Acid Schiff (PAS) and strongly red with Masson's Trichrome stain. This lesion was most prevalent in rats that also had tubular protein casts in the medulla.

In the liver, treatment-related findings included bile duct hyperplasia and hepatocyte hypertrophy, in addition to hepatocyte focal necrosis, oval cell hyperplasia and periportal fibrosis. Additional pathological findings included bone marrow hyperplasia, heart mineralization, glandular stomach mineralization, cellular histiocytic infiltration in the lung and ovarian cyst.

2-year study in rats ${ }^{13}$

Several organs were affected by pulegone treatment.

Urinary Bladder: In the urinary bladder the incidences of urinary bladder papilloma and of papilloma or carci- noma (combined) were significantly increased in females when compared to concurrent controls. The papillomas were exophytic in nature, with a central core of fibrovascular tissue. The neoplastic cells showed minimal atypia and rare mitotic figures. The transitional cell carcinomas had a more solid growth pattern that largely filled the lumen of the bladder lumen. The cords of neoplastic cells sometimes invaded through the basement membrane zones into underlying connective tissue. Cellular atypia and the numbers of mitotic figures were increased.

Kidney: In the kidney, hyaline glomerulopathy and nephropathy were treatment-related findings in both males and females. They were considered important contributing factors to the end-stage renal disease that caused early deaths of most high dose rats. Hyaline glomerulopathy was characterized by a thickening of the glomerular mesangium and, to a lesser degree, the capillary loops by amorphous eosinophilic material, leading to substantial glomerular enlargement in the more severely affected rats, particularly in the females. The material expanding the mesangia was negative with Congo Red for amyloid and was positive with PAS and Masson's Trichrome in the more severely affected rats. A silver stain did not reveal increased basement membrane material or basement membrane 'spikes,' although basement membrane splitting was sometimes present. Affected glomeruli were variably intensely positive for the presence of $\operatorname{IgG}, \operatorname{IgM}$, and $\operatorname{IgA}$ and were negative for complement protein 3. The staining pattern was multifocal within an affected glomerulus, with both the mesangium and capillary loops showing regional positivity. Transmission electron microscopy examination revealed that the glomerular tuft was markedly expanded by amorphous, finely granular, variably dense material occasionally containing small, smooth-margined vacuoles. This material was located on the endothelial surface of the capillary loops and within the mesangium but not within the glomerular basement membrane or on the subepithelial surface. In severely affected glomeruli, the dense material often completely obliterated the mesangium and capillary loops.

Nephropathy was severe in most high-dose rats, particularly in males, consistent with end-stage renal disease. It was characterized by multifocal to diffuse regenerative renal tubules surrounded by a thickened basement membrane, variable thickening of the glomerular mesangium, tubule protein casts, and chronic interstitial inflammatory infiltrates with fibrosis.

Liver: Diffuse hepatocyte cellular alterations were noted in the liver of male and female rats, consisting of a decrease in cell size, increased cytoplasmic basophilia and loss of cytoplasmic glycogen and lipid, and an increase in nuclear size with coarsely clumped chromatin and increased prominence and often number of nucleoli. Karyomegaly was also sometimes observed. Apoptotic hepatocytes, characterized by a shrunken, rounded, hypereosinophilic cellular look with pyknotic nuclei, were also found in the affected rats. Additional findings in the liver included fatty change, bile duct cysts, hepatocyte necrosis, oval cell hyperplasia, 
bile duct hyperplasia, and portal fibrosis.

Nose: Olfactory epithelial degeneration in the nose was observed in high dosed stop exposure males and all dosed females. Other nasal lesions included respiratory metaplasia of the olfactory epithelium, nasal inflammation, and glandular dilatation.

Pancreas: Acinar atrophy was observed in the pancreas, and the incidences of acinar hyperplasia were decreased.

Stomach: Treatment-related findings in the forestomach included inflammation, ulcers, mineralization, epithelial hyperplasia, and perforations. In the glandular stomach, the incidence of inflammation was increased in treated animals compared to the control groups.

Ovary: In the ovary, ovarian atrophy was observed, and was characterized by a decrease in the number of follicles, corpora hemorrhagica, and corpora lutea.

Other organs: Other treatment-related findings included mesenteric lymph node hemorrhage and bone marrow hyperplasia and pituitary gland pars distalis adenoma. There was decreased incidence of mammary gland fibroadenoma and thyroid gland C-cell hyperplasia.

2-week study in mice ${ }^{13}$

Treatment-related findings were noted in the liver, including cytoplasmic vacuolization, diffuse fatty change, necrosis, hemorrhage, inflammation, bile duct hyperplasia, and mineralization.

3-month study in mice $^{13}$

No histopathologic lesions were observed that could be attributed to the administration of pulegone.

2-year study in mice ${ }^{13}$

Liver: In the liver, treatment-related findings in males and females included increased incidences in hepatocellular adenomas and hepatoblastomas in the treated groups when compared to the concurrent controls. In addition, more animals in the treated groups had multiple hepatocellular adenomas and hepatoblastomas than in the control group(s). Hepatocellular adenomas were variably sized nodular lesions composed of well differentiated, neoplastic hepatocytes that usually compressed the adjacent hepatic parenchyma. Portal areas and central veins were typically absent. Additional findings in the liver included clear cell, eosinophilic, and mixed cell foci; focal fatty change; centrilobular hepatocyte hypertrophy; intravascular hepatocyte; necrosis; pigmentation; bile duct cyst and hyperplasia; and oval cell hyperplasia.

Kidney: In the kidney, treatment-related findings in all treated males and mid-high dosed females included hyaline glomerulopathy, mineralization, nephropathy, and congestion of the glomerulus. Hyaline glomerulopathy was characterized by a thickening of the glomerular mesangium and, to a lesser degree, the capillary loops by amorphous eosinophilic material, resulting in significant glomerular enlargement in the more severely affected animals. The material expanding the mesangium was negative for amyloid and was positive for PAS and Masson's Trichrome stains in the more severely affected mice. In addition, there was positive staining of the mesangium with anti-IgM antibody. Electron mi- croscopy revealed that in a kidney with mild lesions, there were irregular dense deposits expanding the glomerular mesangium and extending into the capillary subendothelial space; the glomerular basement membrane was irregularly thickened, even at some distance from the dense deposits. The material was finely granular, amorphous, and variably dense and was suggestive of immune complex deposition. In a kidney with marked lesions, the ultrastructural changes included large, well circumscribed accumulations of tightly packed tubules in longitudinal and cross-sectional arrays. These tubules were highly structured, nonbranching, curvilinear, fibrillary deposits forming discrete, variably sized, principally extracellular bundles. These bundles of fibrils were oriented in parallel rows, often swirling with a characteristic "fingerprint" pattern. These structures markedly expanded the glomeruli and obliterated the capillary lumens.

Osteoma and osteosarcoma: Single incidences of nasal osteomas were observed in treated male and female mice; no nasal osteomas have been seen in historical control mice. A single bone osteoma was observed in a treated female. In addition, a few osteosarcomas were also observed in treated females.

Nose: Additional treatment-related findings included nasal lesions, including olfactory epithelial degeneration of the nose, inflammation, nerve atrophy, and olfactory epithelial metaplasia of the nose.

Stomach: In the forestomach, treatment-related findings included squamous hyperplasia, inflammation, and ulcer.

Other organs: Other lesions associated with treatment included mineralization of the heart, corneal inflammation, ovarian atrophy, and hematopoietic cell proliferation in the spleen.

\section{Kava Kava}

Kava kava (Piper methysticum) has been cultivated in the South Pacific for its rootstock, also referred to as the stump. Kava kava is traditionally used throughout the Pacific Islands as a beverage in ceremonies or religious occasions. Its use has also been popular due to its anxiolytic activity and sedative effects ${ }^{48}$.

Although there are limited available studies on toxicity in experimental animals, most of these studies suggested potential hepatotoxicity. Hepatotoxicity was also reported in humans including functional disturbances, hepatitis, cirrhosis, and liver failure. Some authors suggested that hepatotoxicity risk could be dose related.

Toxicity of kava kava has been attributed to CYP2D6 deficiency seen in 7-9\% of Caucasian, 5.5\% of Western European, almost $1 \%$ of Asian, and less than $1 \%$ of Polynesian populations. No data on the carcinogenicity of kava kava in experimental animals or epidemiology studies in humans were found in the literature 49 .

In the 2-week studies, groups of 5 male and female rats and mice were administered 0, 0.125, 0.25, 0.5, 1 and $2 \mathrm{~g} / \mathrm{kg}$ Kava Kava extract by gavage. For the 3-month study, same doses were selected on groups of 10 male and female rats 
and mice.

For the 2-year studies, groups of 50 male and 50 female rats and mice were dosed at concentrations of $0,0.3,1.0 \mathrm{~g} /$ $\mathrm{kg}$ (rats) and $0,0.25,0.5,1.0 \mathrm{~g} / \mathrm{kg}$ (mice), respectively.

\section{Pathology findings}

2-week study in rats 21,49

The only histopathology change observed after 2 weeks of exposure was minimal hepatocellular hypertrophy in rats.

3-month study in rats 21,49

The major target organ was the liver of treated female rats and included increased dose-related incidence and severity of hepatocellular hypertrophy. These changes were accompanied by depletion of glycogen and amphophilic cytoplasm of the hepatocytes.

2-year study in rats ${ }^{21,49}$

There was an increase in the incidences of testicular interstitial (Leydig) cell adenoma with significantly increased incidences of bilateral interstitial cell adenoma in treated groups when compared to the concurrent control group. There were several lesions that were observed in the livers (Figs. 22-24): hepatocellular hypertrophy, mainly in a centrilobular distribution; centrilobular fatty change, characterized by hepatocytes with large, clear cytoplasmic vacuoles; and cystic degeneration, characterized by multilocular cystic areas resulting from rupture of adjacent hepatocytes. Metaplasia of pancreatic acinar cells to a hepatocytic morphology, characterized by small clusters of normal hepatocytes adjacent to islets of Langerhans (Fig. 25), was present in male/female treated rats, but not in controls.

Additional findings related to Kava-kava treatment included inflammation, ulcer, and epithelial hyperplasia in the forestomach; nephropathy and transitional epithelial hyperplasia of the pelvis of the kidney; and retinal degeneration in the eye. There were decreased incidences of pars distalis adenoma in the pituitary gland and fibroadenoma of the mammary gland.

2-week study in mice 21,49

The only histopathology change observed after 2 weeks of exposure was minimal hepatocellular hypertrophy in mice.

3-month study in mice 21,49

In both males and females, there was a dose-related increase in the incidence of centrilobular hypertrophy, characterized by ground-glass cytoplasmic eosinophilia and increased hepatocellular size and a decrease in cytoplasmic glycogen.

2-year study in mice 21,49

Increased incidences of neoplastic lesions were observed in the livers of mice, and included: hepatoblastomas (in males), hepatocellular adenomas (in males and females) and hepatocellular carcinomas (in females).

Hepatocellular adenomas were characterized by welldifferentiated, neoplastic hepatocytes that formed nodular lesions that typically compressed the adjacent hepatic parenchyma. Portal areas and central veins were typically ab- sent, and mild cellular atypia was often present.

Hepatocellular carcinomas were variably well demarcated from the surrounding hepatic parenchyma and were composed of neoplastic hepatocytes that displayed mild to marked cellular and nuclear pleomorphism and mitoses (Fig. 26). The predominant pattern was trabecular, but glandular or solid patterns of growth were also evident focally. Necrosis and metastases to the lung were also evident in the affected mice. Hepatoblasotmas developed within hepatocellular adenomas or carcinomas and were composed of basophilic fusiform cells (Fig. 27). Cystic areas filled with blood, mitoses and necrosis were also common. Non-neoplastic lesions of the liver included centrilobular hypertrophy, which displayed marked variability between lobes and in the same lobe. Additional findings included eosinophilic foci, small clusters of angiectasis, and randomly distributed areas of necrosis of hepatocytes (not related to neoplasia). In the forestomach, the incidences of chronic inflammation, epithelial hyperplasia, and erosion were significantly increased.

\section{Milk Thistle}

Milk thistle, Silybum marianum, a member of the Aster family, is a tall edible plant. The fruits of this plant contain the relatively water-insoluble flavonolignans, known as silymarin complex (silybin, isosilybin, silydianin, silychristin, and isosilychristin). This complex constitutes $70 \%$ of the milk thistle extract. Silymarin possesses an antiproliferative and antioxidant effects, by reducing free radical production and lipid peroxidation 28,42 .

Milk thistle has been used in herbal medicine for the treatment of liver diseases (alcoholic and viral hepatitis, cirrhosis) and gallbladder disorders. Some other potentially beneficial effects included reducing breast, cervical, and prostate cancer cell growth, as well as reducing insulin resistance, and lowering cholesterol levels. Additional reported uses include treatment for malarial fever, bronchitis, uterine congestion, and varicose veins and also as a milk production stimulant for nursing mothers ${ }^{42}$. Protective effects against UVB-induced carcinogenesis were also reported.

No toxicity studies of milk thistle, its extracts, or its known polyphenolic constituents have been reported in the literature. In humans, clinical trials reported few side effects including laxative effects and allergic reactions. There are no 2-year carcinogenicity studies of milk thistle reported in the literature ${ }^{28}$.

In the NTP 3-month study, groups of 10 male and 10 female rats and mice were fed diets containing $0,3,125$, $6,250,12,500,25,000$, or 50,000 ppm milk thistle extract for 14 weeks.

In the 2-year study, groups of 50 male and 50 female rats and mice were fed diets containing $0,12,500,25,000$, or 50,000 ppm milk thistle extract for 105 to 106 weeks.

\section{Pathology findings}

3-month study in mice and rats 28 


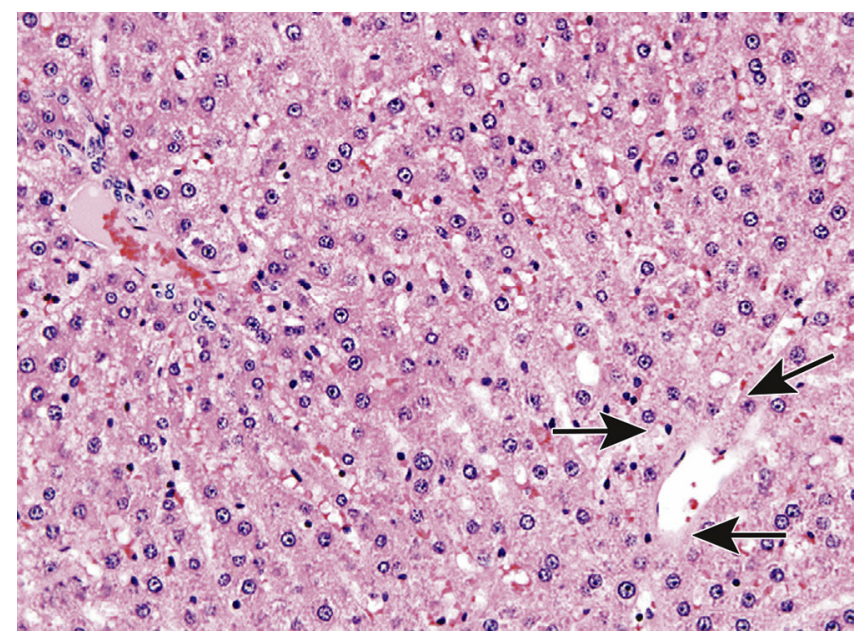

Fig. 22. Photomicrograph of a liver section from a control male rat from the 2-year Kava Kava study. Note (arrows), the normal aspect of the hepatocytes in the centrilobular region. Compare with Fig. 23. $\times 32$. H\&E. Reproduced with permission from Behl et al., Food Chem Toxicol. 2011; 49(11): 2820-29.

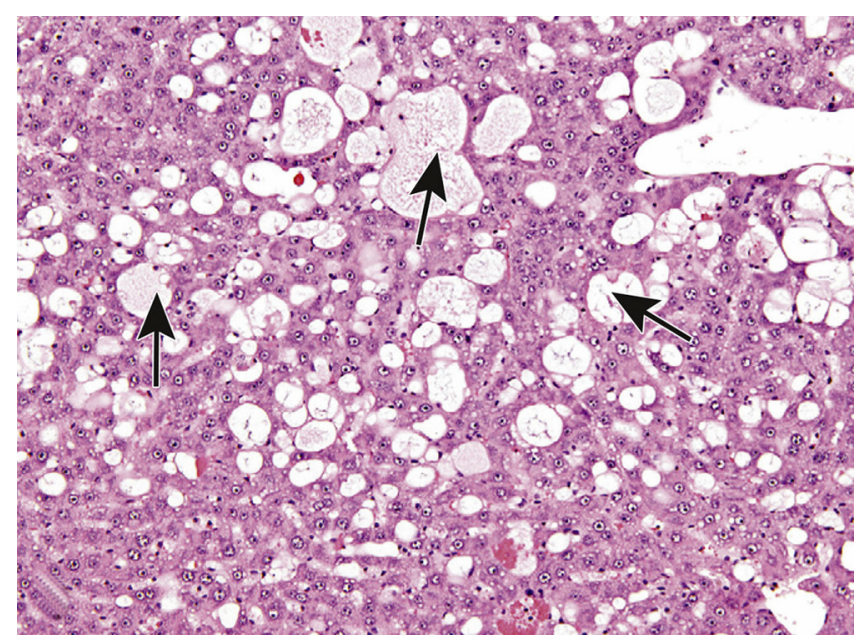

Fig. 24. Photomicrograph of a liver section from a male rat treated with $1 \mathrm{~g} / \mathrm{kg}$ Kava Kava for 2 years. Note (arrows), mild (grade 2) cystic degeneration. $\times 16$. H\&E. Reproduced with permission from Behl et al., Food Chem Toxicol. 2011; 49(11): 2820-29. served.

No exposure-related histopathologic lesions were ob-

2-year study in rats 28,42

There were increases in the incidence of clear cell, eosinophilic, and mixed cell foci in the livers of female rats, but there was no indication for an increase in liver tumors. There was a significantly decreased incidence of mammary gland fibroadenoma (consisting of both ductular and/or alveolar epithelium and fibrous connective tissue), adenoma, or carcinoma (combined) in female rats. Previous NTP studies showed that decrease in body weight might have an association with decreased incidence of mammary gland

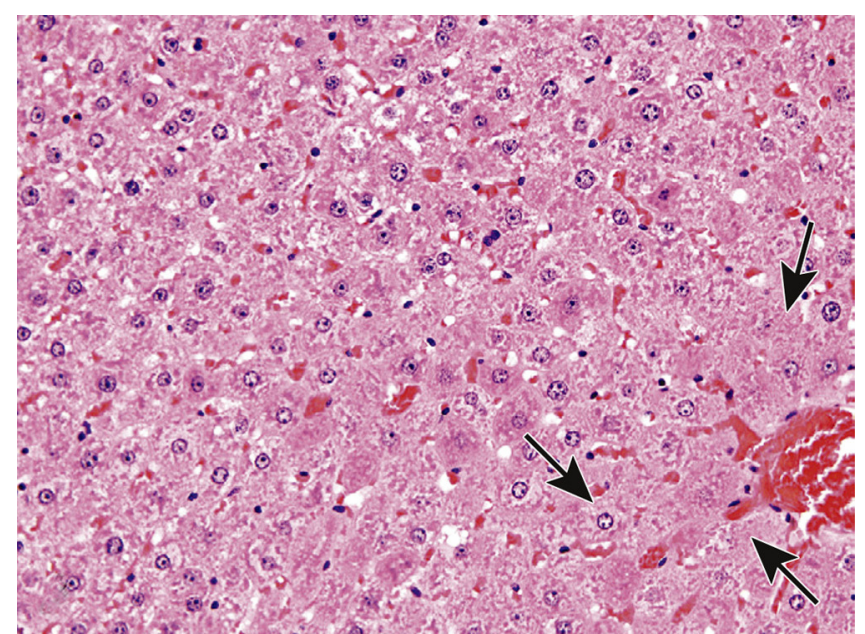

Fig. 23. Photomicrograph of a liver section from a female rat treated with $1 \mathrm{~g} / \mathrm{kg}$ Kava Kava for 2 years. Note (arrows), mild (grade 2) centrilobular hepatocytic hypertrophy. Compare with Fig. 22. $\times 32$. H\&E. Reproduced with permission from Behl et al., Food Chem Toxicol. 2011; 49(11): 2820-29.

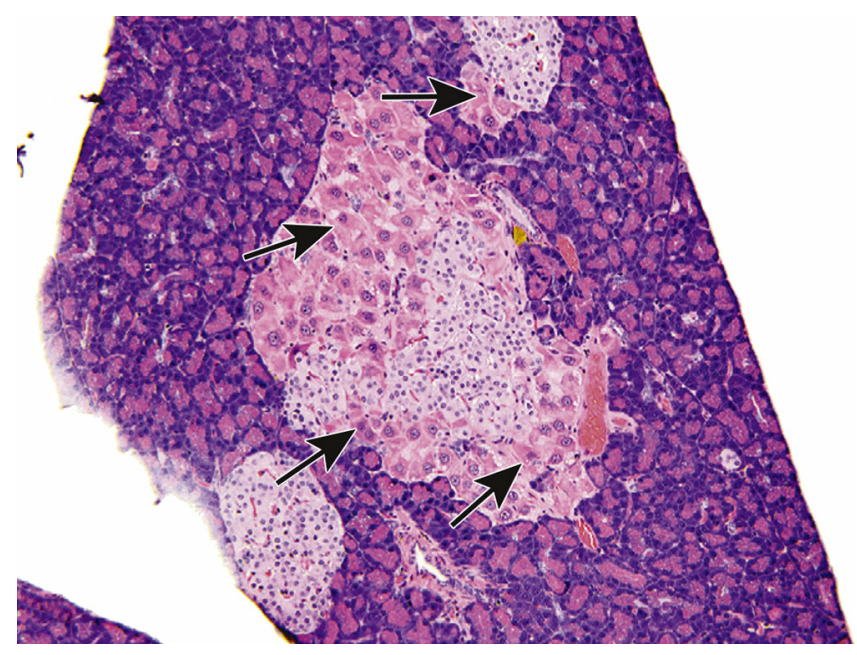

Fig. 25. Photomicrograph of minimal (grade 1) metaplasia of pancreatic acinar cells to a hepatocytic morphology (arrows) from a female rat treated with $1 \mathrm{~g} / \mathrm{kg}$ Kava Kava for 2 years. The metaplasia was always found in the acinar cells proximal to the islets. $\times 16$. H\&E. Reproduced with permission from Behl et al., Food Chem Toxicol. 2011; 49(11): 2820-29.

neoplasms. However, the effect may also be related to milk thistle extract exposure.

In addition, there was a decreased incidence of mixed inflammatory cell infiltration in males, and a decreased incidence of bile duct hyperplasia in males and females.

There was a decreased incidence of pigmentation in the mesenteric lymph nodes. Special stains revealed that the pigment was a combination of iron, lipofuscin, and other black pigment. The decreased incidence of pigmentation was suggested to be the result of the antioxidative effect of 

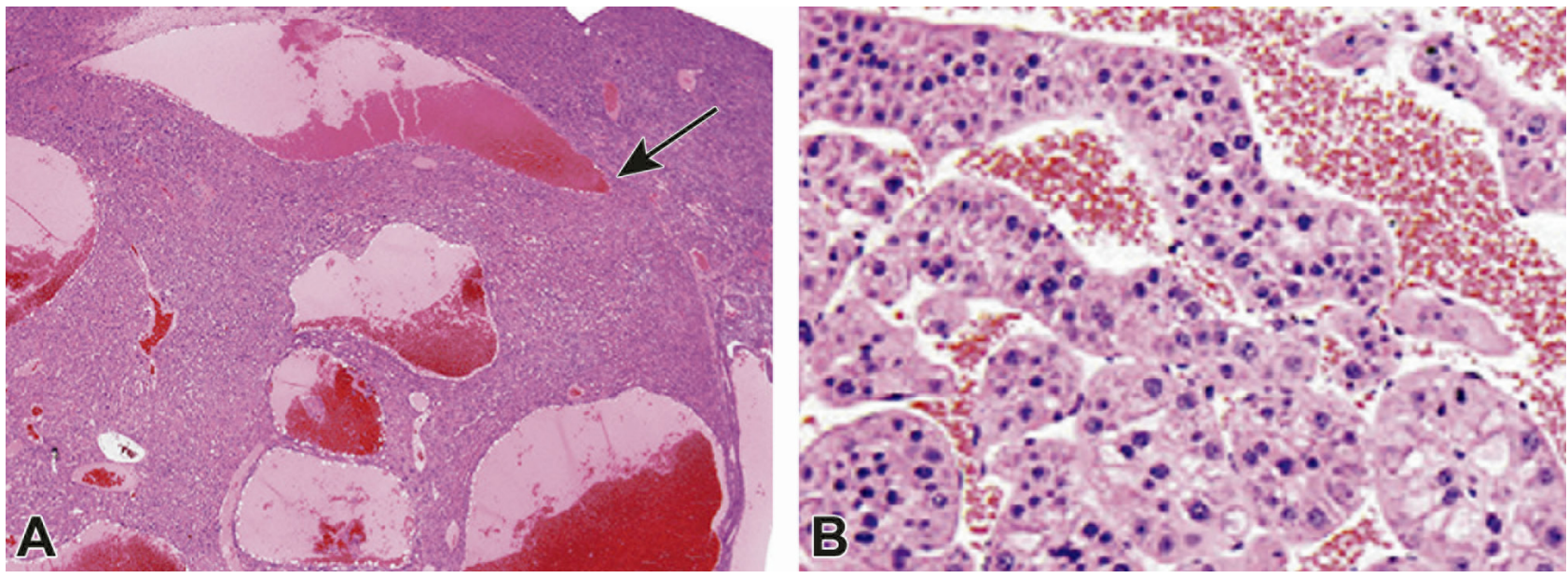

Fig. 26. Photomicrographs of hepatocellular carcinoma from a male mouse treated with $0.25 \mathrm{mg} / \mathrm{kg}$ Kava Kava for 2 years. Fig. 26A: Note (arrow), margins of the carcinoma compressing the adjacent normal tissue. $\times 2$. Fig. 26B: Higher magnification of Fig. 26A. Note (arrows) the trabecular architecture displayed by the neoplastic cells. $\times 10$. H\&E. Reproduced with permission from Behl et al., Food Chem Toxicol. 2011; 49(11): 2820-29.
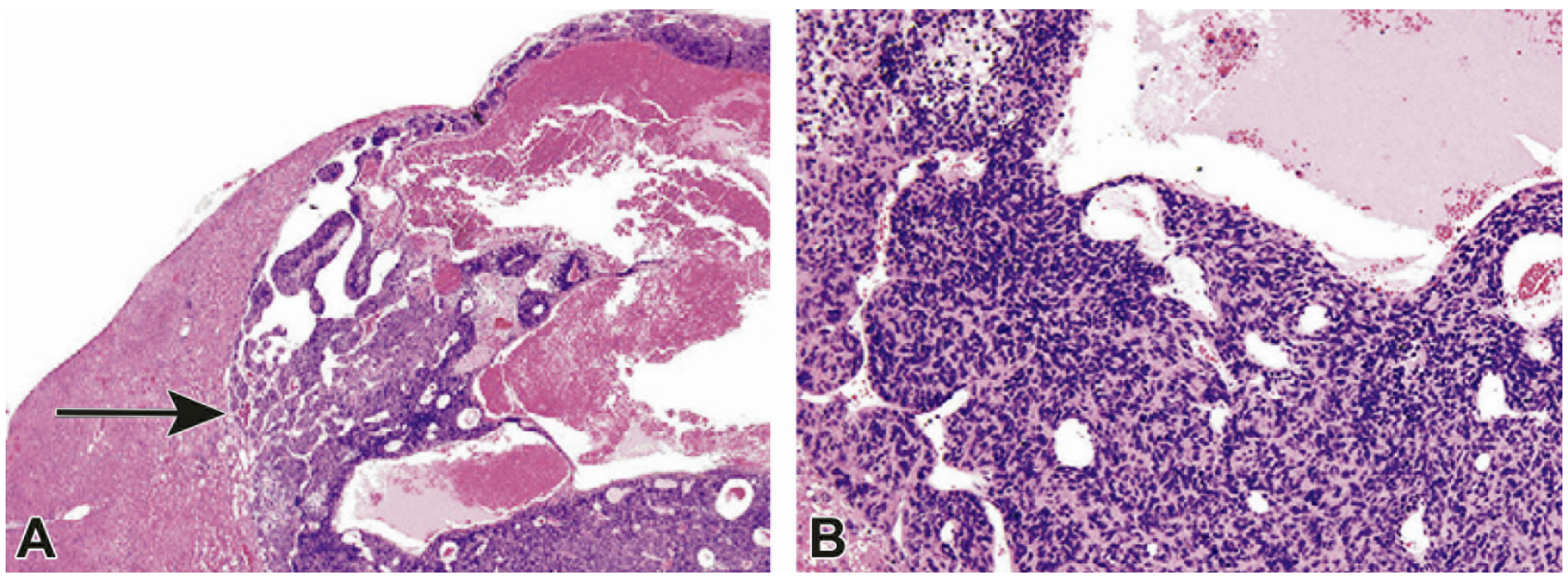

Fig. 27. Photomicrograph of hepatoblastoma from a male mouse treated with $1 \mathrm{mg} / \mathrm{kg} \mathrm{Kava} \mathrm{Kava} \mathrm{for} 2$ years (arrow). Note the hyperbasophilic appearance of the mass due to presence of basophilic fusiform cells with a high nucleus to cytoplasmic (N:C) ratio. Fig. 27A: X 2 . Fig. 27B: note the presence of basophilic fusiform cells with a high nucleus to cytoplasmic. $\times 10$. H\&E. Reproduced with permission from Behl et al., Food Chem Toxicol. 2011; 49(11): 2820-29.

milk thistle, leading to reduced age-related degradation of the subcellular membranous structure ${ }^{50}$.

2-year study in mice 28,42

Significantly decreased incidences of hepatocellular adenoma, hepatocellular carcinoma, and hepatocellular adenoma or carcinoma (combined) occurred in male mice exposed to milk thistle when compared to concurrent controls.

\section{Indole-3-carbinol 15}

Indole-3-carbinol (I3C) is a breakdown product of glucosinolate glucobrassicin. It is found in cruciferous vegetables of the Brassica genus, including brussels sprouts, cauliflower, cabbage, and broccoli. Cruciferous vegetables consumption has been associated with a decreased risk of cancer in humans. $\mathrm{I} 3 \mathrm{C}$ is promoted and investigated due to its various claimed effects including cancer prevention, antioxidant protection, reinforcement of the body's immune system, and enhancement of hepatic and intestinal detoxification of chemicals.

I3C induces the expression and activity of cytochrome P450 (CYP)1A1 in liver, mammary, and colon; and 1A2, $1 \mathrm{~B} 1,2 \mathrm{~B} 1 / 2$, and $3 \mathrm{~A}$ in the liver. I3C induction of CYP enzymes thus metabolizes carcinogenic chemicals in various tissues. CYP-mediated estrogen metabolism is also believed to be a protective effect of $\mathrm{I} 3 \mathrm{C}$ against estrogen-responsive tumors.

Several carcinogenicity studies were conducted in vari- 
ous animal models to assess $\mathrm{I} 3 \mathrm{C}$ inhibitory and promotional effect. I3C promoted aflatoxin B1-initiated hepatocarcinogenesis, thyroid gland, colon and pancreatic tumors and inhibited tumorigenesis in multiple tissues including the lung and liver. Decreased incidence of endometrial adenocarcinoma and mammary gland tumors were observed as well. I3C is believed to be non-mutagenic.

In the 3-month studies conducted by the NTP, groups of 10 male and 10 female $\mathrm{F} 344 / \mathrm{N}$ rats and $\mathrm{B} 6 \mathrm{C} 3 \mathrm{~F} 1 / \mathrm{N}$ mice were administered $0,18.75,37.5,75,150$, or $300 \mathrm{mg}$ (rats) and $0,15.6,31.25,62.5,125$, or 250 (mice) indole-3-carbinol/ $\mathrm{kg}$ body weight in corn oil by gavage, 5 days per week for 14 weeks.

In the 2-year studies, groups of 50 male and 50 female Harlan Sprague Dawley rats and B6C3F1/N mice were administered $0,75,150$, or $300 \mathrm{mg}$ (rats) and $0,62.5,125$, or $250 \mathrm{mg}$ (mice) indole-3-carbinol/kg body weight in corn oil by gavage, 5 days per week for 104 or 105 weeks.

\section{Pathology findings}

3-month study in F344/N rats ${ }^{15,51}$

In the small intestine, there were significant increased incidences of lamina propria lipidosis and lymphatic ectasia in the duodenum and in the jejunum of males and females (Fig. 28a, b) rats exposed to indole-3-carbinol when compared to the controls. This was accompanied by significantly increased incidences of dilatation of the mesenteric lymphatic vessels (Fig. 28c, d). Positive staining for Oil Red O and Sudan Black confirmed the material withing the dilated vessels was lipid (Fig. 28e, f). Electron microscopy showed extracellular lipid accumulation within the villar lamina propria, lacteals, and within villar macrophages.

3-month study in B6C3F1/N mice ${ }^{15}$

No histopathologic lesions were attributed to the administration of indole-3-carbinol.

2-year study in Sprague-Dawley rats ${ }^{15}$

There was an increased incidence of adenocarcinoma of the uterus and squamous metaplasia of the endometrium (of minimal to moderate severity) in treated animals when compared to the concurrent control group. There was also a positive trend for fibroma or fibrosarcoma (combined) in the skin of female rats and increased incidence of fibroma in the skin of high-dosed females compared to controls. There was increased incidence of lymphatic ectasia in the duodenum and jejunum of the small intestine of both sexes, accompanied by an increased incidence of lymphatic ectasia in the mesenteric lymph nodes. In the liver, there was an increased incidence of clear cell and eosinophilic foci in female rats and bile duct cysts in male rats. The incidences of follicular cell hypertrophy in the thyroid gland were significantly increased in males, and the severities of the lesion increased with increasing dose.

2-year study in $\mathrm{B} 6 \mathrm{C} 3 \mathrm{~F} 1 / \mathrm{N}$ mice ${ }^{15}$

There were increased incidences of hepatocellular adenomas, hepatocellular carcinomas, and hepatoblastomas in male mice exposed to indole-3-carbinol when compared to the concurrent control group. In addition, there was an increased incidence for clear cell focus in male mice and eosinophilic focus in female mice.

In the glandular stomach, the incidences of epithelium hyperplasia, chronic inflammation, and pigmentation were significantly increased in both male and female mice. In the nose, there was an increased incidence of nerve atrophy, respiratory metaplasia of the olfactory epithelium, atrophy of the olfactory epithelium, respiratory epithelium hyperplasia in males and females. There was an increased incidence of necrosis of the olfactory epithelium and respiratory epithelium hyaline droplet accumulation in males, and increased inflammation in females.

\section{Turmeric Oleoresin}

Turmeric is derived from the plant Curcuma longa, related to the ginger family (Zingiberaceae), which originated from India and is currently grown in several other parts of the world, including Southeast Asia, China, and Latin America $^{29,52}$. It is available as the whole rhizome or bulb from the plant, as a ground powder, and as the oleoresin. The major component in all turmeric oleoresins is curcuminoid, primarily curcumin.

Turmeric has gained significant popularity due to its potential benefits as an anticancer, antibiotic, anti-inflammatory, and anti-aging agent as suggested by several in vitro and in vivo studies and clinical trials.

Turmeric has been used for decades for the treatment of sprain and inflammation in India, although clinical trials have not been conducted to determine its efficacy ${ }^{29}$.

Curcumin has been reported to protect against lipid peroxidation in isolated hepatocytes induced by acetaminophen as well as smoke-induced DNA damage in human lymphocytes. Topically applied curcumin is believed to inhibit neoplastic promotion by 12-0-tetra-decanoylphorbol13 -acetate in mouse skin and by phorbol esters in mouse fibroblast. Turmeric oleoresin was not mutagenic in most systems in which it was tested. There have been no carcinogenicity studies in experimental animals or humans reported in the literature 29 .

In the 3-month studies, groups of 10 male and $10 \mathrm{fe}-$ male rats and mice received $0,1,000,5,000,25,000,10,000$, or $50,000 \mathrm{ppm}$ turmeric oleoresin in feed 5 days per week for 13 weeks. In the 2-year studies, groups of 60 male and 60 female $\mathrm{F} 344 / \mathrm{N}$ rats and $\mathrm{B} 6 \mathrm{C} 3 \mathrm{~F} 1$ mice were fed diets containing 2,000, 10,000, or 50,000 ppm turmeric oleoresin for 103 (mice), 104 (male rats) or 103 (female rats) weeks.

\section{Pathology findings}

13-week study in rats 29

Hyperplasia of the mucosal epithelium was observed in cecum and colon of both sexes.

13-week study in mice 29

There were no chemical-related histopathology changes.

2-year study in rats 7,29

Treatment related non-neoplastic lesions were observed 
a

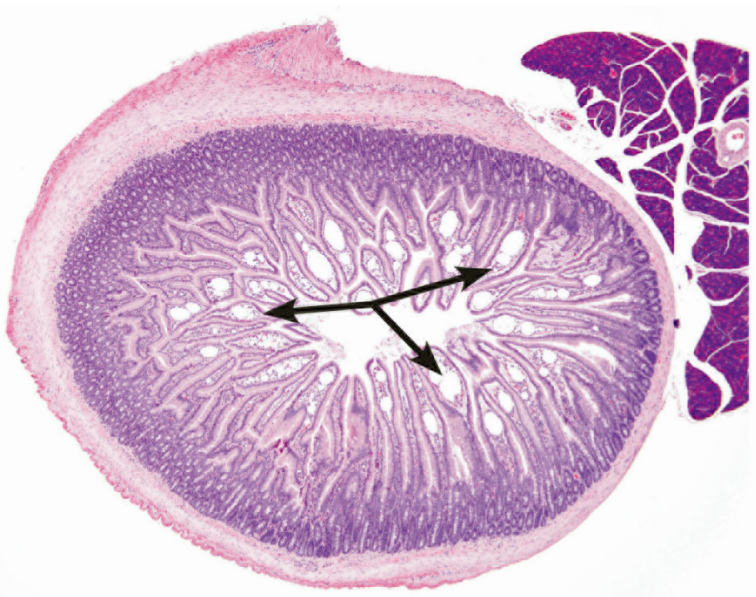

C

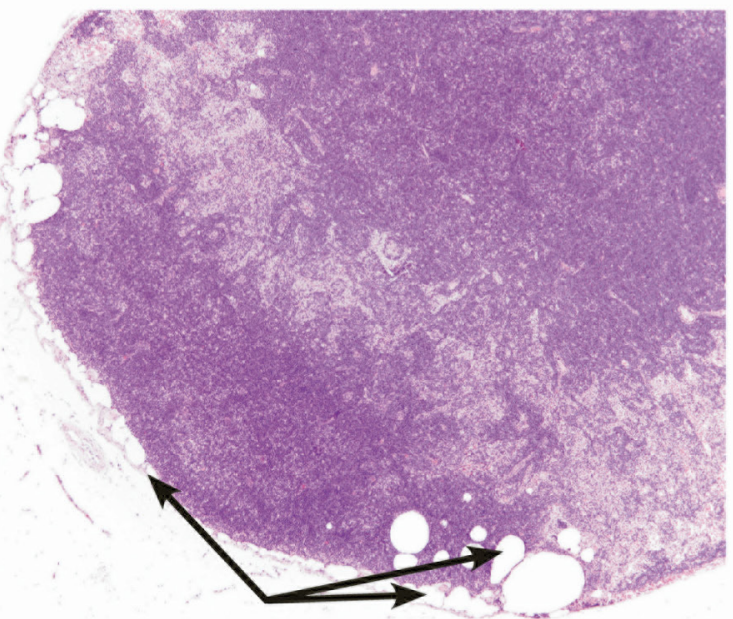

e

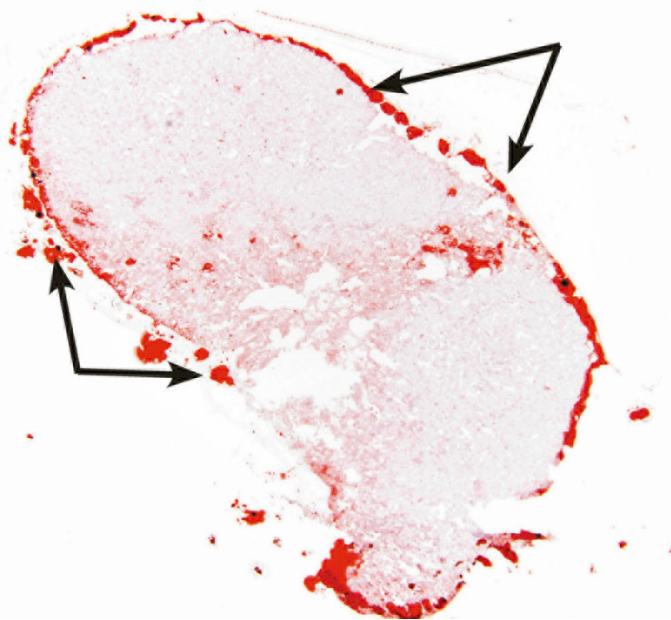

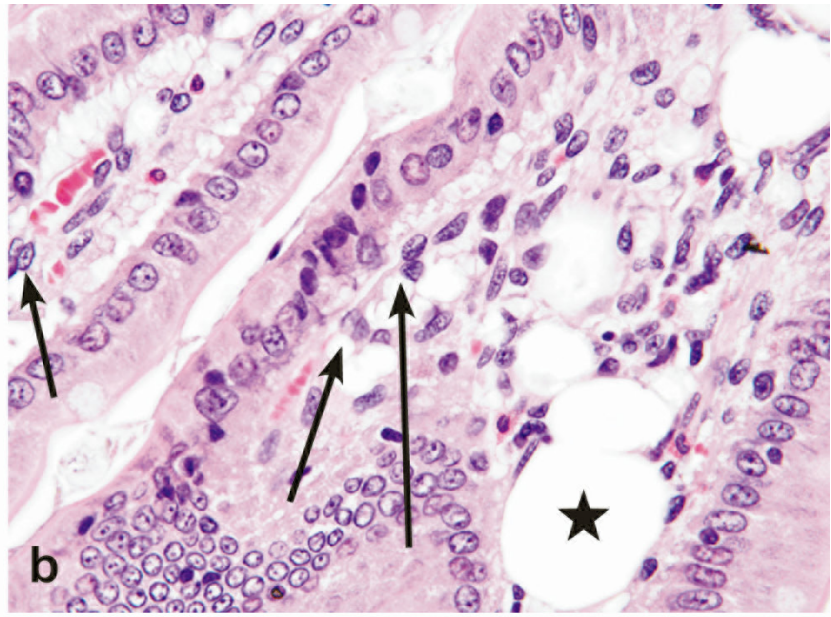

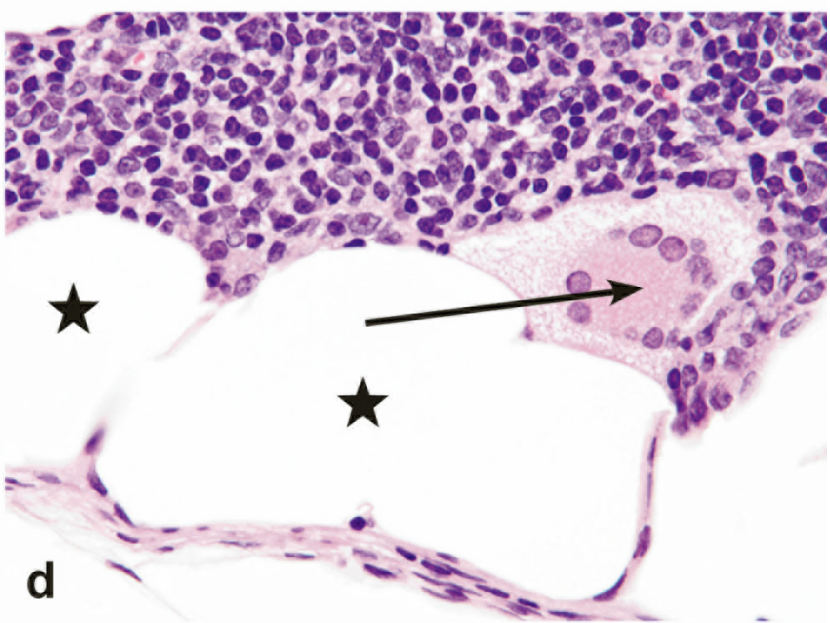

f

Fig. 28. Representative photomicrographs of lesions in the small intestine and mesenteric lymph nodes of rats exposed to a 3-month treatment of $300 \mathrm{mg} / \mathrm{kg}$ indole-3-carbinol via oral gavage. (a) Duodenum; moderate ectasia of villous lacteals (lymphangiectasis) (arrows). Original objective $4 \times$, H\&E. (b) Duodenum; lymphangiectasis (stars). Note vacuolated macrophages within the lamina propria (arrows). Original objective 40×, H\&E. (c) Mesenteric lymph node; moderate lymphangiectasis of the subcapsular sinus (arrows). Original objective 4×, H\&E. (d) Mesenteric lymph node; lymphangiectasis of the subcapsular sinus (asterisks). Note vacuolated multinucleated giant cells (arrow). Original objective $40 \times, \mathrm{H} \& \mathrm{E}$ ). (e and f) Mesenteric lymph node; large aggregates and pools of red staining material within subcapsular sinuses (arrows) are consistent with excessive lipid accumulation (lipidosis). Note grade 4 lymphangiectasis. Original objectives $2 \times$ (e) and 40× (f), Oil Red O. Reproduced with permission from Boyle et al., Toxicol Pathol. 2012; 40(4): 561-76. 
in the gastrointestinal tract. In males, there was increased incidence of ulcers, hyperplasia, and hyperkeratosis of the forestomach. Ulcers, chronic active inflammation, and hyperplasia of the cecum was observed in both genders in the cecum, and in males only in the colon. There was an increased incidence of clitoral gland adenomas in females, but clitoral gland carcinomas and hyperplasia were not significantly different between groups of rats exposed to turmeric oleoresin and the concurrent control group.

\section{2-year study in mice ${ }^{7,29}$}

Increased incidence of hepatocellular neoplasms was observed in both sexes. However, since these changes were not significant by trend statistic, and the incidence of hepatic foci was not increased in treated groups, the evidence for carcinogenic activity of turmeric oleoresin was only equivocal. Female mice treated with the highest dose had increased incidence of thyroid gland follicular cell hyperplasia.

\section{Senna $^{53}$}

Senna is a leaf of Senna alexandrina P. Mill (Leguminosae) and it is available over the counter as a laxative stimulant and tea. The bacterial enzymes break down sennosides in the intestines and release the active form, rhein-9-anthrone, which possesses a laxative effect. High dose of senna may be used for bowel preparation prior to colonoscopy or surgery.

Most genotoxicity studies showed negative results; however, some in vitro studies reported positive results in bacterial gene mutation and in mammalian cells. Subacute exposure to senna resulted in liver and kidney toxicity. In subchronic exposure study in rats, hyperplastic (reversible) changes in the forestomach and large intestine were observed.

Some case studies reported allergic reactions and hepatitis associated with the excessive use of senna in humans.

Some authors suggested an association between laxatives and colon cancer. Various studies have shown that senna extract might increase neoplastic formation, while other studies showed that sena or sennosides had no effect on the incidence of neoplastic formation.

In the 5-week study, groups of 5 male and 5 female C57BL/6NTac mice at 6-7 weeks of age were administered $0,625,1,250,2,500,5,000$, or 10,000 ppm senna for 29 days.

Groups of 25 male and 25 female P53 $+/-$ mice at $6-8$ weeks of age were administered $0,100,300,1,000,3,000$ or $10,000 \mathrm{ppm}$ senna were for 40 weeks.

\section{Pathology findings}

5-week study in C57BL/6NTac mice 53

There was an increased incidence of epithelial hyperplasia of the cecum and colon in both sexes, and of the rectum in female mice. This hyperplasia was characterized by increased numbers of epithelial cells, which resulted in increased crypt depth and mucosal thickening. Numerous mitotic figures were evident.

40-week study in p53+/- mice 53
There was an increased incidence of epithelial hyperplasia of the colon and cecum in both sexes.

\section{Disclosure of Potential Conflicts of Interest: None.}

Acknowledgments: The authors thank N. Walker, NIEHS, and A. Brix, EPL, for the review of the chapter. The photographs are reproduced by permission of the journals as noted in each figure legend. This article does not contain clinical studies or patient data. The statements, opinions, or conclusions contained in this article do not necessarily represent the statements, opinions, or conclusions of NIEHS or NIH.

\section{References}

1. Petrovska BB. Historical review of medicinal plants' usage. Pharmacogn Rev. 6: 1-5. 2012. [Medline] [CrossRef]

2. Sewell RDE, and Rafieian-Kopaei M. The history and ups and downs of herbal medicines usage. J HerbMed Pharmacol. 3: 1-3. 2014.

3. U. S. Food and Drug Administration. Dietary Supplements. 2020, website: https://www.fda.gov/food/dietary-supplements

4. National Institutes of Health Office of Dietary Supplements Office of Dietary Substances. 2020, website: https://ods. od.nih.gov/

5. Saad B, Azaizeh H, Abu-Hijleh G, and Said O. Safety of traditional arab herbal medicine. Evid Based Complement Alternat Med. 3: 433-439. 2006. [Medline] [CrossRef]

6. Barnes PM, Bloom B, and Nahin RL. Complementary and alternative medicine use among adults and children: United States, 2007. Natl Health Stat Rep. (12): 1-23. 2008. [Medline]

7. Dunnick JK, and Nyska A. The toxicity and pathology of selected dietary herbal medicines. Toxicol Pathol. 41: 374 386. 2013. [Medline] [CrossRef]

8. Navarro VJ, and Seeff LB. Liver injury induced by herbal complementary and alternative medicine. Clin Liver Dis. 17: 715-735, x. 2013. [Medline] [CrossRef]

9. Roytman MM, Poerzgen P, and Navarro V. Botanicals and Hepatotoxicity. Clin Pharmacol Ther. 104: 458-469. 2018. [Medline] [CrossRef]

10. National Toxicology Program. Toxicology and carcinogenesis studies of goldenseal root powder (Hydrastis Canadensis) in F344/N rats and B6C3F1 mice (feed studies). Natl Toxicol Program Tech Rep Ser. 562: 1-188. 2010. [Medline]

11. National Toxicology Program. Toxicology and carcinogenesis studies of Ginkgo biloba extract (CAS No. 90045-36-6) in $\mathrm{F} 344 / \mathrm{N}$ rats and B6C3F1/N mice (Gavage studies). Natl Toxicol Program Tech Rep Ser. 578: 1-183. 2013. [Medline]

12. National Toxicology Program. Toxicology and carcinogenesis studies of riddelliine (CAS No. 23246-96-0) in F344/N rats and $\mathrm{B} 6 \mathrm{C} 3 \mathrm{~F} 1$ mice (gavage studies). Natl Toxicol Program Tech Rep Ser. 508: 1-280. 2003. [Medline]

13. National Toxicology Program. Toxicology and carcinogenesis studies of pulegone (CASRN 89-82-7) in F344/ $\mathrm{N}$ rats and B6C3F1 mice (gavage studies). Natl Toxicol Program Tech Rep Ser. 563: 1-202. 2011.

14. National Toxicology Program. Toxicology and Carcino- 
genesis Studies of Kava Kava Extract (CASRN 9000-38-8) in F344/N Rats and B6C3F1 Mice (Gavage Studies). Natl Toxicol Program Tech Rep Ser. 571: 1-178. 2012.

15. National Toxicology Program. Toxicology studies of Indole-3-Carbinol (CASRN 700-06-1) in $\mathrm{F} 344 / \mathrm{N}$ rats and B6C3F1/N mice and toxicology and carcinogenesis studies of Indole-3-Carbinol in Harlan Sprague Dawley rats and B6C3F1/N mice (gavage studies). Natl Toxicol Program Tech Rep Ser. 584: 1-200. 2017.

16. International Agency for Research on Cancer Some drugs and herbal products. IARC monograph. 2015, website: http://publications.iarc.fr/132

17. California Office of Environmental Health Hazard Assessment. The Proposition 65 List. 2020, website: https://oehha. ca.gov/proposition-65/proposition-65-list. 2020

18. Chen S, Wan L, Couch L, Lin H, Li Y, Dobrovolsky VN, Mei N, and Guo L. Mechanism study of goldenseal-associated DNA damage. Toxicol Lett. 221: 64-72. 2013. [Medline] [CrossRef]

19. Hoenerhoff MJ, Pandiri AR, Snyder SA, Hong HH, Ton TV, Peddada S, Shockley K, Witt K, Chan P, Rider C, Kooistra L, Nyska A, and Sills RC. Hepatocellular carcinomas in B6C3F1 mice treated with Ginkgo biloba extract for two years differ from spontaneous liver tumors in cancer gene mutations and genomic pathways. Toxicol Pathol. 41: 826841. 2013. [Medline] [CrossRef]

20. Yamashita H, Surapureddi S, Kovi RC, Bhusari S, Ton TV, Li JL, Shockley KR, Peddada SD, Gerrish KE, Rider CV, Hoenerhoff MJ, Sills RC, and Pandiri AR. Unique microRNA alterations in hepatocellular carcinomas arising either spontaneously or due to chronic exposure to Ginkgo biloba extract (GBE) in B6C3F1/N mice. Arch Toxicol. 94: 25232541. 2020. [Medline] [CrossRef]

21. Behl M, Nyska A, Chhabra RS, Travlos GS, Fomby LM, Sparrow BR, Hejtmancik MR, and Chan PC. Liver toxicity and carcinogenicity in $\mathrm{F} 344 / \mathrm{N}$ rats and $\mathrm{B} 6 \mathrm{C} 3 \mathrm{~F} 1$ mice exposed to Kava Kava. Food Chem Toxicol. 49: 2820-2829. 2011. [Medline] [CrossRef]

22. National Toxicology Program. Toxicology and carcinogenesis studies of a nondecolorized whole leaf extract of Aloe barbadensis miller (Aloe Vera) (CASRN ALOEVLEAFEXT) in F344/N rats and B6C3F1 mice (drinking water study). Natl Toxicol Program Tech Rep Ser. 577: 1-266. 2013.

23. National Toxicology Program. Toxicology study of senna (CASRN 8013-11-4) in C57BL/6NTac mice and toxicology and carcinogenesis study of senna in genetically modified C3B6.129F1/Tac-Trp53tm1Brd N12 haploinsufficient mice (feed studies). Natl Toxicol Program GMM Rep Ser. GMM15: 1-314. 2013.

24. Boudreau MD, Mellick PW, Olson GR, Felton RP, Thorn BT, and Beland FA. Clear evidence of carcinogenic activity by a whole-leaf extract of Aloe barbadensis miller (aloe vera) in F344/N rats. Toxicol Sci. 131: 26-39. 2013. [Medline] [CrossRef]

25. Boudreau MD, Olson GR, Tryndyak VP, Bryant MS, Felton RP, and Beland FA. From the cover: aloin, a component of the aloe vera plant leaf, induces pathological changes and modulates the composition of microbiota in the largeiIntestines of F344/N male rats. Toxicol Sci. 158: 302-318. 2017. [Medline] [CrossRef]

26. Pandiri AR, Sills RC, Hoenerhoff MJ, Peddada SD, Ton TV,
Hong HH, Flake GP, Malarkey DE, Olson GR, Pogribny IP, Walker NJ, and Boudreau MD. Aloe vera non-decolorized whole leaf extract-induced large intestinal tumors in F344 rats share similar molecular pathways with human sporadic colorectal tumors. Toxicol Pathol. 39: 1065-1074. 2011. [Medline] [CrossRef]

27. National Toxicology Program. Photocarcinogenesis study of aloe vera [CAS NO. 72-1(Aloe-emodin)] in SKH-1 mice (simulated solar light and topical application study). Natl Toxicol Program Tech Rep Ser. 553: 1-206. 2010.

28. National Toxicology Program. Toxicology and carcinogenesis studies of milk thistle extract (CAS No. 84604-20-6) in F344/N rats and B6C3F1 mice (feed studies). Natl Toxicol Program Tech Rep Ser. 565: 1-177. 2011. [Medline]

29. National Toxicology Program. NTP toxicology and carcinogenesis studies of turmeric oleoresin (CAS No. 8024-371) (major component $79 \%-85 \%$ curcumin, CAS No. 458 $37-7$ ) in $\mathrm{F} 344 / \mathrm{N}$ rats and B6C3F1 mice (feed studies). Natl Toxicol Program Tech Rep Ser. 427: 1-275. 1993. [Medline]

30. National Toxicology Program. Toxicology studies of Green Tea extract in F344/NTTac rats and $\mathrm{B} 6 \mathrm{C} 3 \mathrm{~F} / \mathrm{N} 1$ mice and toxicology and carcinogenesis studies of green tea extract in Wistar Han[Crl:Wi(Han)] rats and B6C3F1 mice (gavage studies). Natl Toxicol Program Tech Rep Ser. 585: 1-192. 2016.

31. U. S. National Library of Medicine ClinicalTrials.gov. 2020, website: https://clinicaltrials.gov/

32. Menon VP, and Sudheer AR. Antioxidant and anti-inflammatory properties of curcumin. Adv Exp Med Biol. 595: 105-125. 2007. [Medline] [CrossRef]

33. Féher J, and Lengyel G. Silymarin in the prevention and treatment of liver diseases and primary liver cancer. Curr Pharm Biotechnol. 13: 210-217. 2012. [Medline] [CrossRef]

34. Asbaghi O, Fouladvand F, Moradi S, Ashtary-Larky D, Choghakhori R, and Abbasnezhad A. Effect of green tea extract on lipid profile in patients with type 2 diabetes mellitus: a systematic review and meta-analysis. Diabetes Metab Syndr. 14: 293-301. 2020. [Medline] [CrossRef]

35. National Center for Complementary and Integrative Health. 2020, website: https://www.nccih.nih.gov/

36. Dunnick JK, Kissling G, Gerken DK, Vallant MA, and Nyska A. Cardiotoxicity of Ma Huang/caffeine or ephedrine/caffeine in a rodent model system. Toxicol Pathol. 35: 657-664. 2007. [Medline] [CrossRef]

37. Nyska A, Murphy E, Foley JF, Collins BJ, Petranka J, Howden R, Hanlon P, and Dunnick JK. Acute hemorrhagic myocardial necrosis and sudden death of rats exposed to a combination of ephedrine and caffeine. Toxicol Sci. 83: 388-396. 2005. [Medline] [CrossRef]

38. Rider CV, Nyska A, Cora MC, Kissling GE, Smith C, Travlos GS, Hejtmancik MR, Fomby LM, Colleton CA, Ryan MJ, Kooistra L, Morrison JP, and Chan PC. Toxicity and carcinogenicity studies of Ginkgo biloba extract in rat and mouse: liver, thyroid, and nose are targets. Toxicol Pathol. 42: 830-843. 2014. [Medline] [CrossRef]

39. Mei N, Guo X, Ren Z, Kobayashi D, Wada K, and Guo L. Review of Ginkgo biloba-induced toxicity, from experimental studies to human case reports. J Environ Sci Health Part C Environ Carcinog Ecotoxicol Rev. 35: 1-28. 2017. [Medline] [CrossRef]

40. Smith JV, and Luo Y. Studies on molecular mechanisms 
of Ginkgo biloba extract. Appl Microbiol Biotechnol. 64: 465-472. 2004. [Medline] [CrossRef]

41. Chan PC, Ramot Y, Malarkey DE, Blackshear P, Kissling GE, Travlos G, and Nyska A. Fourteen-week toxicity study of green tea extract in rats and mice. Toxicol Pathol. 38: 1070-1084. 2010. [Medline] [CrossRef]

42. Dunnick JK, Singh B, Nyska A, Peckham J, Kissling GE, and Sanders JM. Investigating the potential for toxicity from long-term use of the herbal products, goldenseal and milk thistle. Toxicol Pathol. 39: 398-409. 2011. [Medline] [CrossRef]

43. National Toxicology Program. Photocarcinogenesis study of aloe vera [CAS NO. 481-72-1(Aloe-emodin)] in SKH-1 mice (simulated solar light and topical application study). Natl Toxicol Program Tech Rep Ser. 553: 7-33, 5-97, 9-103 passim. 2010.

44. Chan PC, Haseman JK, Prejean JD, and Nyska A. Toxicity and carcinogenicity of riddelliine in rats and mice. Toxicol Lett. 144: 295-311. 2003. [Medline] [CrossRef]

45. Thoolen B, Maronpot RR, Harada T, Nyska A, Rousseaux C, Nolte T, Malarkey DE, Kaufmann W, Küttler K, Deschl U, Nakae D, Gregson R, Vinlove MP, Brix AE, Singh B, Belpoggi F, and Ward JM. Proliferative and nonproliferative lesions of the rat and mouse hepatobiliary system. Toxicol Pathol. 38(Suppl): 5S-81S. 2010. [Medline] [CrossRef]

46. Nyska A, Moomaw CR, Foley JF, Maronpot RR, Malarkey DE, Cummings CA, Peddada S, Moyer CF, Allen DG, Travlos G, and Chan PC. The hepatic endothelial carcinogen riddelliine induces endothelial apoptosis, mitosis, $\mathrm{S}$ phase, and p53 and hepatocytic vascular endothelial growth factor expression after short-term exposure. Toxicol Appl Pharmacol. 184: 153-164. 2002. [Medline] [CrossRef]

47. Krishna M. Microscopic anatomy of the liver. Clin Liver Dis (Hoboken). 2(Suppl 1): S4-S7. 2013. [Medline] [CrossRef]

48. Clayton NP, Yoshizawa K, Kissling GE, Burka LT, Chan $\mathrm{PC}$, and Nyska A. Immunohistochemical analysis of expressions of hepatic cytochrome P450 in F344 rats following oral treatment with kava extract. Exp Toxicol Pathol. 58: 223-236. 2007. [Medline] [CrossRef]

49. National Toxicology Program. Toxicology and carcinogenesis studies of kava kava extract (CAS No. 9000-38-8) in F344/N rats and B6C3F1 mice (gavage studies). Natl Toxicol Program Tech Rep Ser. 571: 1-186. 2012.

50. Fraschini F, Demartini G, and Esposti D. Pharmacology of Silymarin. Clin Drug Investig. 22: 51-65. 2002. [CrossRef]

51. Boyle MC, Crabbs TA, Wyde ME, Painter JT, Hill GD, Malarkey DE, Lieuallen WG, and Nyska A. Intestinal lymphangiectasis and lipidosis in rats following subchronic exposure to indole-3-carbinol via oral gavage. Toxicol Pathol. 40: 561-576. 2012. [Medline] [CrossRef]

52. Kotha RR, and Luthria DL. Curcumin: biological, pharmaceutical, nutraceutical, and analytical aspects. Molecules. 24: 2930. 2019. [Medline] [CrossRef]

53. Surh I, Brix A, French JE, Collins BJ, Sanders JM, Vallant M, and Dunnick JK. Toxicology and carcinogenesis study of senna in C3B6.129F1-Trp53 tm1Brd N12 haploinsufficient mice. Toxicol Pathol. 41: 770-778. 2013. [Medline] [CrossRef] 